LBL-36395

UC- 1600

\title{
Industrial Sector Energy Conservation Programs in the People's Republic of China during the Seventh Five-Year Plan (1986-1990)
}

\author{
Liu Zhiping \\ Energy Research Institute \\ State Planning Commission \\ Beijing, PRC \\ Jonathan E. Sinton, Yang Fuqiang, \\ Mark D. Levine, and Michael K. Ting \\ Energy Analysis Program \\ Energy and Environment Division \\ Lawrence Berkeley Laboratory \\ University of California \\ Berkeley, California 94720
}

September 1994 


\section{DISCLAIMER}

This report was prepared as an account of work sponsored by an agency of the United States Government. Neither the United States Government nor any agency thereof, nor any of their employees, make any warranty, express or implied, or assumes any legal liability or responsibility for the accuracy, completeness, or usefulness of any information, apparatus, product, or process disciosed, or represents that its use would not infringe privately owned rights. Reference herein to any specific commercial product, process, or service by trade name, trademark, manufacturer, or otherwise does not necessarily constitute or imply its endorsement, recommendation, or favoring by the United States Government or any agency thereof. The views and opinions of authors expressed herein do not necessarily state or reflect those of the United States Government or any agency thereof. 


\section{DISCLAIMER}

Portions of this document may be illegible in electronic image products. Images are produced from the best available original document. 


\section{Contents}

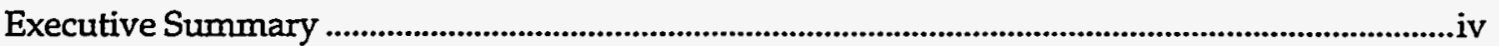

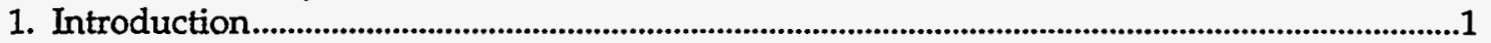

2. Energy Conservation During the Sixth and Seventh Five-Year Plans ....................................2

Organization and Implementation of Energy Conservation ..............................................10

Industrial Energy Conservation Investment Funding..............................................................15

3. Case Studies of Energy Conservation Investments by Industry ..................................................18

Ferrous Metals Manufacturing Subsector .........................................................................18

Non-Ferrous Metals Mining and Manufacturing Subsector ................................................22

Chemicals Manufacturing Subsector .....................................................................................24

Building Materials Manufacturing Subsector .....................................................................26

4. Economic Evaluation of Investments...................................................................................................30

Analytic Methodology: Gross and Net Unit Investment ...................................................30

Uncertainties In Conservation Investment And Energy Savings Data ..............................33

Capital Construction Investments...........................................................................................35

5. Problems Encountered in the Seventh Five-Year Plan Investment Programs ..........................50

Inadequate capital investment................................................................................................51

Distortion of energy prices ..........................................................................................................51

Weak restrictions on energy-intensive equipment .................................................................51

Low energy-efficiency in rural industry ...................................................................................52

Inconsistent evaluation method.......................................................................................52

Lack of managerial and other incentives ..................................................................................52

References.

\section{Figures}

Figure 1. Energy Conservation and Supply Investment, 1981-1990.................................................

Figure 2. Energy Conservation Institutional Framework, 1993 .................................................... 12

Figure 3. Share of Direct Investment in Central Government Capital Construction Investment in Energy Conservation................................................................................................................. 16

\section{Tables}

Table 1. Energy Conservation Investment, 1981-1990 .....................................................................

Table 2. Energy Conservation Policy Documents, 1981-1990 ....................................................

Table 3. Sources of Energy Conservation Investment Funds ....................................................... 15

Table 4. Economic Energy Intensities and Apparent Net Energy Savings.................................. 20

Table 5. Physical Energy Intensity of Selected Industrial Products, 1981-1990 .......................... 21

Table 6. Energy Consumption of Building Materials Industries ................................................... 26

Table 7. Energy Conservation Projects by Industrial Subsector, 7th FYP ..................................32

Table 8. Unit Investment, Alternatives to Capital Construction Projects (1986-1990) .................33

Table 9. Capital Construction Investment in Energy Conservation, 1981-1990............................ 36

Table 10. Unit Investment, Capital Constuction Projects ..................................................................37

Table 11. Technical Updating Investment in Energy Conservation, 1981-1990............................ 44

Table 12. Unit Investment, Technical Updating Projects .....................................................................45

Table 13. Furnace and Kiln Types Renovated in the Seventh FYP by Industry ...........................48 


\section{Acknowledgments}

The authors would like to thank Prof. Lu Yingzhong of PAI Corporation and Steve Weil of the Energy Analysis Program, Lawrence Berkeley Laboratory for their valuable comments on a draft of this paper. Thanks are due also to colleagues in China too numerous to mention, and to Ted Gartner and Karen Olson of the Energy Analysis Program, for editing assistance. 


\section{Executive Summary}

Already the world's third largest user of primary commercial energy, China consumes energy at a per capita rate only one-third of the world's average. This low per capita rate, combined with economic growth rates exceeding those in any other country (13\% GNP growth in 1993), suggest that unprecedented expansion in energy demand can be expected, bringing with it serious consequences for the environment, infrastructure, energy markets, and the economy within and beyond China's borders.

In 1992, 1120 million tons of standard coal equivalent ${ }^{1}$ (Mtce) of primary energy were consumed. The Chinese government predicts that in the year 2000, the annual energy demand will be 1700 Mtce, with an output of primary energy of 1300-1400. Under this scenario, energy savings of 300-400 Mtce would be required to meet development goals without further degradation of environmental quality. Chinese planners realized at the end of the 1970s that end-use efficiencies needed to improve significantly if these goals were to be met. Consequently they developed farreaching policies for the 6th and 7th Five-Year Plans (1981-1985 and 1986-1990) that would place equal emphasis on both development and conservation of energy supplies.

During the Sixth FYP policymakers invested as much as $11 \%$ of energy supply investment into a state-run program of energy conservation projects and this figure only fell to $8 \%$ during the Seventh FYP, reflecting the serious commitment of the Chinese government to conservation. Throughout the 1980s, other policies were developed by a range of government bodies, from the State Planning Commission (SPC), to central government line ministries, central banks, and provincial governments (all under the guidance of the Office of Energy Conservation of the State Council (China's highest governmental body). Principal among these measures were administrative orders to eliminate inefficient equipment and processes and adopt efficient ones; the promotion and rewarding of conservation efforts; establishment of a network of energy conservation offices extending from the highest levels of government to the management of large state-owned enterprises; and support for monitoring and development of efficiency standards.

While achievements have been impressive-conservation has been institutionalized in China as in no other nation-it was not brought about without difficulties. Six complex issues planners faced were (1) lack of specific energy savings policies and regulations; (2) lack of incentives for energy savings; (3) lack of attention from top officers of enterprises; (4) lack of energy conservation funding; (5) lack of training for energy management staff and equipment operators; and (6) energy shortages that impeded energy savings.

lOne tce $=29.31 \mathrm{GJ}=5.15 \mathrm{bbl}$ oil equivalent. In this paper energy units are converted to tce, reflecting the dominance of coal in China's fuel mix. 
Those who pursue efficiency goals must contend with a strong bias toward energy supply, as in other countries. Funding for conservation investment throughout both periods remained strong, while the burden of investment began to shift from the central government (whose share in conservation investments fell from $65 \%$ during the Sixth FYP to $48 \%$ during the Seventh) to local governments and enterprises, as the central government tried to leverage its increasingly scarce funds. As of $1988,48 \%$ of enterprises relied on self-raised funds for energy-related technical updating projects and only $8 \%$ relied solely on government loans.

The state-sponsored program of energy conservation investments was responsible for a significant portion of apparent improvements in the energy efficiency of China's industrial economy. The reported results from conservation investments in the Seventh FYP, for example, were equivalent to $11 \%$ of the energy saved in 1990 (calculated by comparing energy and output value ratios in 1985 and 1990).

\section{A sector-by-sector analysis}

In this paper we examine China's four largest energy-consuming industries: ferrous and non-ferrous metals, chemicals, and building materials manufacturing.

Investments in capital construction projects in the Seventh FYP increased by about half in real terms over the Sixth FYP. Nearly $15 \mathrm{Mtce} / \mathrm{yr}$ of energy conservation capacity resulted from Seventh FYP capital construction energy conservation projects. Almost two-thirds of that conservation capacity came from cogeneration, fuel gas emissions recovery, and district heating projects. The most energyintensive industries, iron and steel, chemicals, aluminum, and paper, undertook projects to convert waste heat and pressure in useful electricity. Outmoded and inefficient boilers were replaced or renovated to improve district heat. Industrial furnaces and kilns in the metallurgical, chemical, and building materials industries were renovated to reduce heat losses and to improve efficiencies. Newer technologies, including computer controls and advanced combustion devices, were introduced.

Ferrous Metals Manufacturing: Conservation projects offered important multiple benefits: nearly one-third of a large increase in steel production resulted from conservation investments that increased production capacity. Similar investments helped reduce steel and iron production energy intensity by $1.6 \%$ annually during the Seventh FYP.

Technological advancements, i.e., more efficient power generation and gas recovery, pulverized coal injection in blast furnaces, continuous casting and rolling processes, and renovated boilers and furnaces, have brought some of China's metalsprocessing plants to levels comparable to those of the developed world.

Non-Ferrous Metals Mining and Manufacturing: This electricity-intensive subsector (electricity accounts for over half of total energy use) exhibited only 
modest declines in energy intensity between 1980-1990. Conservation investments included renovated mining equipment, electricity conservation at aluminum plants and imports of advanced technologies.

Chemical Manufacturing: Energy consumption in the chemical subsector is dominated by production of fertilizers and raw materials. Here China differs from other countries because of the dominance of coal, providing $52 \%$ of energy inputs (including feedstocks) in 1990. Successful demonstration projects from the Sixth FYP were refined during the years following. All large and small ammonia plants, of which the smallest and least efficient produce $60 \%$ of output, underwent renovations that focused on improved gas and heat recovery. The conservation effort at ammonia plants has become a model for small-plant improvements during the Eighth FYP.

Building Materials Manufacturing: Like chemical production, the building materials subsector relies heavily on coal as its energy source. Small-scale cement plants and non-state-owned brick plants consume 80 and $90 \%$ of total energy demand in their industries respectively. Renovations to reduce intensity throughout the subsector included, for cement, reconstruction of kilns, installation of waste heat cogeneration capacity, and improvements to the heat-transfer and drying processes; for plate glass production, the recovery of stack gases for industrial use and residential heating, installation of better insulating materials in smelters and heat-storage chambers; for bricks, recovery of waste heat for drying and improvements, such as computer control systems, to the entire production process.

\section{Economic Analysis}

The Chinese central government's basic criterion for investing in conservation projects was that energy conservation supply be cheaper than new energy supply. To gauge this we prepared indicators on gross unit investment (GUI) and net unit investment (NUI). GUI is the amount of funds needed to build one unit of energy savings capacity taking the entire investment as directed solely at energy savings. NUI is calculated by subtracting from total investment that portion that would have been necessary to achieve an equal increment in production capacity through construction of a reasonable alternative facility and calculating unit investment in energy conservation capacity with the remainder. For instance, GUI and NUI for cogeneration projects in the Seventh FYP were 1257 and 817 yuan/(tce per year of conserved energy).

Because of uncertainties in the basic data, we believe that a more reasonable upper bound to unit cost co-conservation lies somewhere above the GUI figures calculated here. NUI gives what might be considered a lower bound to unit cost, although the often negative values for NUI should be treated carefully. While it is difficult to accept that investors were in effect paid to undertake conservation measures, the difference between GUI and NUI highlights the multiple incentives from the social perspective to make these investments. 
Although we are convinced that the cost of conservation measures during the Sixth and Seventh Five Year Plans was, in fact less than the cost of new energy supply, we have identified the following challenges that must be addressed above the enterprise level in the continuing program of energy conservation investments:

\section{Inadequate capital investment}

Conservation investments in China are only $1.3 \%$ of overall nationwide investments. This compares with $3.5 \%, 2 \%$, and $2 \%$, respectively, for France, the U.S., and Japan, according to one Chinese source.

\section{Distortion of energy prices}

China's two-tier price system encompassed plan prices ${ }^{1}$ fixed by the central government and freely floating market prices. These distortions made cost-benefit comparisons much less useful in ranking investments.

\section{Weak restrictions on energy-intensive equipment}

In spite of regulations requiring that certain categories of extremely energy-intensive equipment be retired from service, no mechanisms for executing the regulations and monitoring compliance were established. The details of implementation were left to local authorities, who were free to interpret the policy statements as strictly or as loosely as was convenient.

\section{Low energy efficiency in rural industry}

The challenge of balancing rural economic development objectives and energy conservation goals should receive more attention from national and local policymakers. With often antiquated (and very energy-intensive) equipment, rural enterprises now account for about half of industrial GOV.

\section{Inconsistent evaluation methods}

Comparisons between energy conservation and energy supply projects are often based on methods that omit such important factors as capital cost, discount rate, operating cost, project lifetime and input price changes. The resulting data are often misleading and encourage investments that are not optimal from a social or national perspective.

\section{Lack of managerial and other incentives}

Energy management requirements in management responsibility contracts, under which enterprise managers assume responsibility for fulfilling contract targets such as output, profits, and tax remittances, have been weak or entirely lacking.

\footnotetext{
${ }^{1}$ In many areas plan prices have virtually disappeared during the past three years.
} 


\section{Introduction}

In 1992, China-already the world's third largest user of primary commercial energyconsumed 1120 million tons of standard coal equivalent (Mtce) ${ }^{1}$ (SSB, 1994). However with a population nearing 1.2 billion, China consumes only 929 kgce of per capita energy, about one-third of the world's average. This low figure implies a tremendous potential for increases in overall consumption, and as per capita income rises, so will per capita energy use. (Thus far China has maintained the growth rate of energy use below that of economic output.) Multiplied by the world's largest population, any small increment in per capita energy use becomes an issue worthy of international notice. Growth in energy consumption associated with recent rapid economic developmentin 1993 GNP grew by over 13\%-has exacerbated already urgent environmental problems that have arisen from energy mining, transport, transformation, and use. The impacts of these issues are felt far beyond China's borders.

Constraints on resources and a less developed infrastructure limit the growth of the energy supply to a rate lower than that needed to fulfill ambitious economic targets. But already the environmental consequences of even current levels of fuel use are already serious. A central government report on long-term energy issues predicted that by the year 2000 domestic energy demand will reach 1700 Mtce, while output of primary energy would reach roughly 1300-1400 Mtce (Lu Gengshan, 1991). Under this scenario, energy savings of $300-400$ Mtce would be required to meet economic development goals without further degradation of environmental quality. The impetus at the national level to invest in energy conservation is quite strong and has long been reflected not only in official pronouncements, but also in the investments and organizational activities of the Chinese government. In the early 1980s the central government began a program of direct investments in industrial energy conservation that continues to the present. In addition, concurrently established governmental and quasi-governmental agencies have pursued conservation through administrative and educational measures.

In Section 2 of this paper we outline the policies and institutions that supported China's program of energy conservation investments in the Sixth and Seventh Five-Year Plans (FYPs) (1981-1985 and 1986-1990). In Section 3 we describe examples of the types of conservation projects pursued in different industrial subsectors. Section 4 presents a simple methodology for comparing the costs of energy conservation to those of energy supply. Further discussion points out the applicability and limitations of this methodology to State Planning Commission published statistical material on the overall results of energy conservation investments. Though problematic, such analysis indicates that energy conservation investments were probably substantially cheaper than investments in equivalent energy supply would have been. We end with a discussion of some of the difficulties encountered in carrying out the conservation investment programs.

\footnotetext{
1 One metric ton of standard coal equivalent equals $29.31 \mathrm{GJ}$. Aggregate energy consumption figures in China refer to coal equivalent because coal is the dominant fuel. Primary electricity (hydroelectricity and nuclear power) are converted at a replacement rate of $0.404 \mathrm{kgce} / \mathrm{kWh}$.
} 


\section{Energy Conservation during the Sixth and Seventh Five-Year Plans ${ }^{2}$}

Chinese energy researchers and planners realized late in the 1970s that future energy supplies would be insufficient to meet the needs of economic development unless energy end-use efficiencies were improved significantly. Consequently, at the very beginning of the 1980s, the central government announced it would place equal emphasis on the development of energy supplies and on energy conservation, with the latter assuming a higher priority in the short term ( $\mathrm{Lu}, 1993)$. Implementation was immediate and, although falling short of the equality with supply investments specified in the statement of principle, a remarkable investment program during the Sixth FYP poured funds equal to $11 \%$ of energy supply investment into energy conservation projects (see Table 1 and Figure 1). Commitment to this course continued through the Seventh FYP, when the ratio declined to slightly less than $8 \%$ (even though conservation investment increased by more than half in real terms), and has continued to grow. These conservation investments have contributed to declines in physical energy intensities observed throughout the 1980s, although accurately quantifying their role is difficult since other factors also contributed to efficiency improvements. Current conservation policy has been refined and formalized and gradually coordinated with that in such areas as production and environmental protection (Levine et al., 1992).

Under the supervision and coordination of the Office of Energy Conservation of the State Council (China's highest governmental body), energy conservation policies were established by the State Planning Commission (SPC), central government line ministries, central banks, and provincial governments. The major policies on energy conservation included:

(i) adjusting sectoral structure and product mix in energy-intensive industries;

(ii) converting oil-using equipment to coal and limiting the direct burning of crude oil and oil products;

(iii) retrofitting existing inefficient equipment;

(iv) removing grossly inefficient equipment from service;

(v) issuing energy-consumption standards for energy-intensive products;

(vi) using a system of rewards and penalties to encourage energy conservation activities;

(vii) providing low-interest loans for energy conservation projects;

(viii) promoting "comprehensive utilization" (zonghe liyong) of energy (e.g., cogeneration);

(ix) improving energy auditing and management, or "soft" energy conservation; and $(x)$ supporting research and development in energy-efficient technologies.

Conservation programs targeted the most energy-intensive industrial subsectors: iron and steel, chemicals, building materials, and power generation. ${ }^{3}$

\footnotetext{
2 This section draws on Yang et al., forthcoming.

3 Together, these four subsectors accounted for $16.3 \%, 17.3 \%, 15.4 \%$ and $3.4 \%$, respectively, of total 1990 energy end-use consumption (Sinton et al., 1992).
} 
Table 1. Energy Conservation Investment, 1981-1990

\begin{tabular}{|c|c|c|c|c|c|}
\hline Year & $\begin{array}{c}\text { Energy } \\
\text { Conservation } \\
\text { Capital Construction } \\
\text { Investment } \\
\text { (billion } 1980 \text { yuan) }\end{array}$ & $\begin{array}{c}\text { Energy } \\
\text { Conservation } \\
\text { Technical Updating } \\
\text { Investment } \\
\text { (billion } 1980 \text { yuan) }\end{array}$ & $\begin{array}{l}\text { Energy } \\
\text { Conservation } \\
\text { Investment } \\
\text { (billion } \\
1980 \text { yuan) }\end{array}$ & $\begin{array}{l}\text { Energy } \\
\text { Supply } \\
\text { Investment } \\
\text { (billion } \\
1980 \text { yuan) }\end{array}$ & $\begin{array}{l}\text { Ratio of } \\
\text { conservation } \\
\text { to supply } \\
\text { investment } \\
\text { (percent) }\end{array}$ \\
\hline 1981 & 0.591 & 0.895 & 1.486 & 14.128 & $10.5 \%$ \\
\hline 1982 & 0.887 & 1.196 & 2.084 & 17.367 & $12.0 \%$ \\
\hline 1983 & $1.482 *$ & 1.327 & 2.809 & 21.319 & $13.2 \%$ \\
\hline 1984 & $1.445^{*}$ & 1.693 & 3.138 & 27.173 & $11.5 \%$ \\
\hline 1985 & $1.375^{*}$ & 1.612 & 2.987 & 33.667 & $8.9 \%$ \\
\hline 1986 & 1.488 & 2.049 & 3.537 & 39.763 & $8.9 \%$ \\
\hline 1987 & 1.782 & 2.211 & 3.993 & 46.118 & $8.7 \%$ \\
\hline 1988 & 1.923 & 2.409 & 4.332 & 50.472 & $8.6 \%$ \\
\hline 1989 & 1.786 & 1.832 & 3.618 & 51.203 & $7.1 \%$ \\
\hline 1990 & 1.929 & 1.972 & 3.901 & 60.492 & $6.4 \%$ \\
\hline 6th FYP & 5.780 & 6.724 & 12.504 & 113.654 & $11.0 \%$ \\
\hline 7th FYP & 8.908 & 10.473 & 19.381 & 248.048 & $7.8 \%$ \\
\hline Total & 14.689 & 17.197 & 31.886 & 361.702 & $8.8 \%$ \\
\hline
\end{tabular}

N.B. Investment data include self-raised investments (non-central government funds). 1980 yuan are calculated using national income deflators for the industrial sector (China Energy Databook). These data are based on statistical reports from energy conservation offices in local planning and economic commissions and may include some local funds allocated as general (nonconservation) loans and direct government expenditures. Coverage of these data is generally more complete than that in the tables that follow.

- Only the sum of investment for the period 1983-1985 was available. The total was divided equally among the three years for the purpose of deflation.

Source: Liu Zhiping, ERI, 1993; SSB, 1991; China Project estimates, EAP, LBL, 1994.

Figure 1. Energy Conservation and Supply Investment, 1981-1990

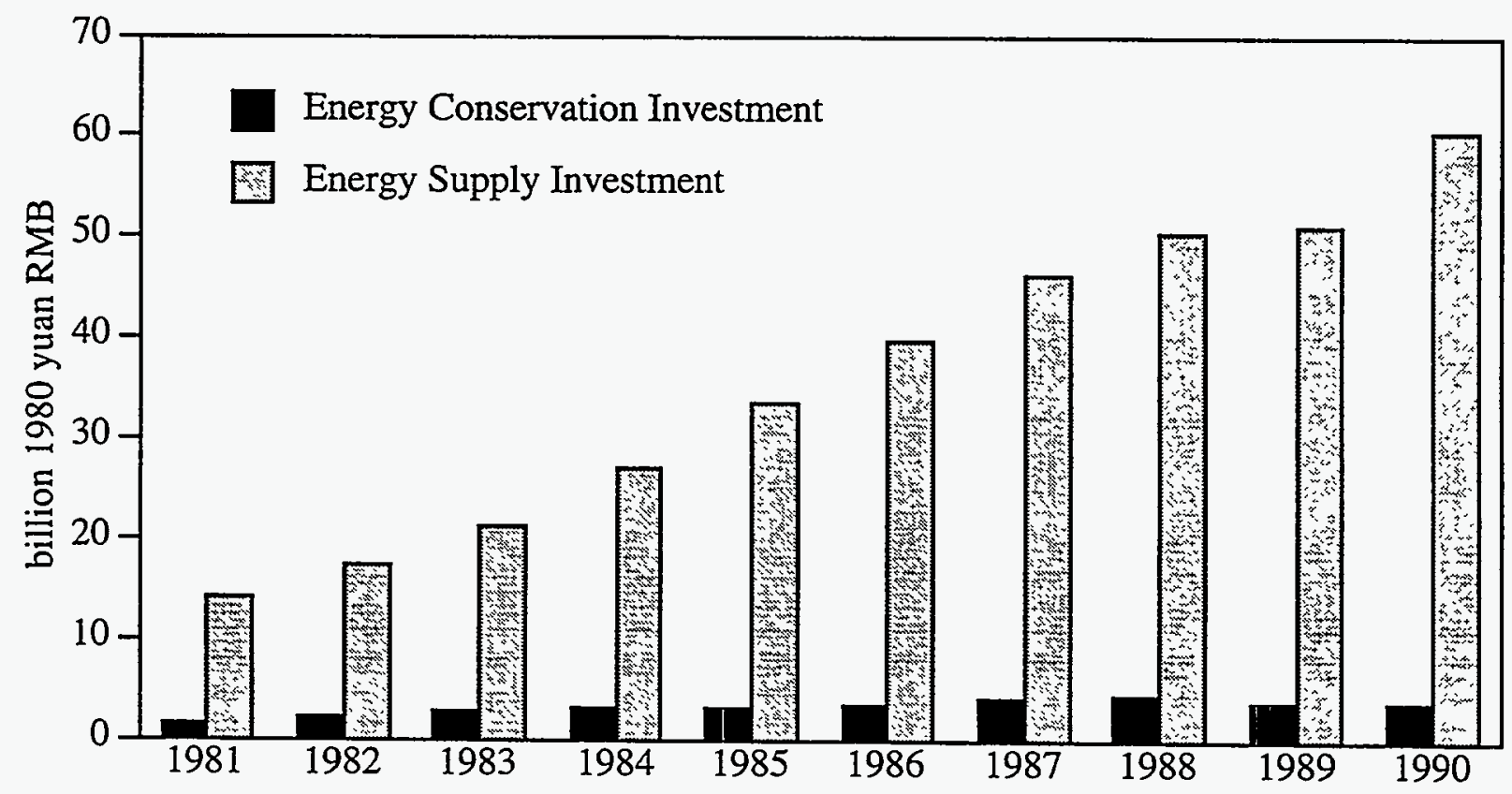

Source: Liu Zhiping, ERI, 1993; SSB, 1991; China Project estimates, EAP, LBL. 
The State Council was much more active in promoting energy conservation in the Seventh FYP than previously (see Table 2). In 1986 it passed the first national comprehensive legislation on energy conservation, the "Temporary Regulations for Energy Conservation Management." Among the key points were

- All enterprises consuming more than $10 \mathrm{ktce}$ per year (so-called key enterprises) were required to have a manager in charge of energy conservation work. All enterprises were also encouraged to maintain records of energy consumption and energy intensities of their products.

- Enterprises using energy imported from other provinces and those with energy consumption per unit product higher than others making similar products were required to spend at least $20 \%$ of their investment funds on energy conservation. All other enterprises were required to spend at least $10 \%$ of their investment funds on energy conservation.

- The National Bureau of Standards and local governments were to establish energy intensity standards for major products to be used in guiding conservation work at enterprises. Performance relative to these standards was to be considered in setting energy allocation quotas for enterprises. ${ }^{4}$

Following the promulgation of the "Temporary Regulations," relevant departments and some provinces drew up similar energy conservation regulations of their own. Examples include the "Regulations Regarding Energy Savings in Coal Mines," issued by the Department of Energy, and the "Zhejiang Province Energy-Saving Regulations" from the Zhejiang provincial government (MOE, 1991).

Another official document, the "Provisions for Further Strengthening Electricity Savings", jointly issued in 1987 by the SPC and the State Economic Commission (SEC), called for limiting electricity allocations to enterprises (Wang Gang, 1991). Electricity consumed in excess of the quota was to be priced at 5 to 10 times the normal price. For electricity saved there were to be awards-depending on the rating level of the enterprise-to be determined in accordance with the "Provisions." 5 Enterprises could decide how to use their allotment of electricity and had the right to sell any that they conserved. Electricity generation using waste heat and pressure was encouraged. This document further required key industrial sectors to set electricity-consumption standards for their main products and equipment, which included $70 \%$ of total industrial electricity energy use.

\footnotetext{
4 Attainment of these standards was later linked to the awarding of financial bonuses. In many cases, implementation fell short of intent. To make nationally set standards meaningful to individual enterprises, standards were tailored by local energy conservation and planning authorities to each enterprise's particular circumstances. Standards were generally tailored so enterprises could meet them without any great improvements in equipment or practices, as long as there were no major mishaps (Sinton, 1994).

5 "National special grade" enterprises could receive awards ranging from $30 \%$ to $50 \%$ of the cost of saved electricity, "national first grade" enterprises, $20 \%$ to $30 \%$, "national second grade" enterprises, $13 \%$ to $15 \%$, and "provincial grade" enterprises would receive $10 \%$ to $13 \%$. Others could receive $8 \%$ to $10 \%$ percent.
} 
Table 2. Energy Conservation Policy Documents (Central Government), 1981-1990

Year

1981 Strictly limit development of small oil refineries and ban backward refining ovens.
Improve energy efficiency in oil refining by banning construction of small, low-technology refineries.
SC

SPC, SEC, SSB

1984 In designing projects earnestly carry out energy conservation and rational utilization of energy, and accelerate revision and supplementing of design standards.

1985 Regarding temporary provisions for certain policies to promote technological advancement at state-run enterprises.

1986 Temporary regulations for energy conservation management.

Encourage administrative efforts within the various ministries to ensure that new projects incorporate energy conservation policy goals.

Give enterprises freedom to choose production technologies, incentives to improve product quality and invest in new technologies (e.g. allow investment in experimental equipment to be counted as a production cost, direct banks to provide low-interest loans, lower tax rates), emphasize projects at large local enterprises, raise depreciation rates, encourage technology transfer.

Intended to provide incentives to enterprises and workers to conserve energy, standardize energy conservation work (see text). Articles include: energy conservation management system, basic energy conservation management work (e.g., statistical reporting), energy supply management, industrial energy use management, residential energy use management, encouraging technological advancement, awards, and propaganda. 
Table 2. Energy Conservation Policy Documents (Central Government), 1981-1990 (continued)

\begin{tabular}{|c|c|c|c|}
\hline Year & Title & Purpose/measures & $\begin{array}{l}\text { Issuing } \\
\text { Authority }\end{array}$ \\
\hline 1986 & $\begin{array}{l}\text { Trial measures for raw materials and fuel } \\
\text { conservation awards for state-run industrial and } \\
\text { transportation enterprises. }\end{array}$ & $\begin{array}{l}\text { Establish rules and conditions for distributing monetary awards for } \\
\text { conservation, generally a percentage of the value of energy saved, with the } \\
\text { percentage varying by industry according to degree of difficulty of } \\
\text { conservation. }\end{array}$ & $\begin{array}{l}\text { MF, MLP, } \\
\quad \text { SEC }\end{array}$ \\
\hline 1986 & $\begin{array}{l}\text { Strengthen management work in urban district } \\
\text { heating. }\end{array}$ & $\begin{array}{l}\text { Expanding district heating management systems, open up new avenues of } \\
\text { financing, and lighten financial burdens of district heat suppliers. }\end{array}$ & $\begin{array}{l}\text { SC, SPC, } \\
\text { MURCEP }\end{array}$ \\
\hline 1986 & $\begin{array}{l}\text { Some tax collection problems relating to energy } \\
\text { conservation management. }\end{array}$ & $\begin{array}{l}\text { Provide policy direction for dealing with some common situations, e.g., charge } \\
\text { special taxes to enterprises that continue to burn crude oil, and allow } \\
\text { enterprises to count repayment of energy conservation loans as production } \\
\text { costs (deduct from pre-tax income). }\end{array}$ & MF \\
\hline 1986 & $\begin{array}{l}\text { Temporary provisions for encouraging the } \\
\text { penetration of energy-conserving electrical } \\
\text { equipment and the halting of production and } \\
\text { removal from service of obsolete equipment. }\end{array}$ & $\begin{array}{l}\text { Articles on production (the Ministry of Machine-Building was made } \\
\text { responsible for setting efficiency standards and monitoring output), } \\
\text { distribution, awards (local economic commissions and machine-building } \\
\text { administrations were made responsible for inspecting facilities and } \\
\text { determining how awards were to be distributed), and fines aimed at increasing } \\
\text { turnover of electrical equipment in industry. }\end{array}$ & $\begin{array}{l}\text { SEC, MF, } \\
\text { MMach, } \\
\text { ICBC }\end{array}$ \\
\hline 1986 & $\begin{array}{l}\text { Further strengthen petroleum consumption } \\
\text { management and reduce use. }\end{array}$ & $\begin{array}{l}\text { Unify allocation and management of petroleum products, limit proliferation of } \\
\text { oil using equipment, control oil transportation equipment, limit oil } \\
\text { consumption (e.g., by increasing taxes), stop construction of small and } \\
\text { inefficient refineries, require local economic commissions to organize } \\
\text { commercial, materials price, and police bureaus to enforce policy. }\end{array}$ & SEC, SPC \\
\hline 1987 & $\begin{array}{l}\text { Temporary provisions for enterprise energy } \\
\text { conservation management grade advancement (or } \\
\text { assigning of a grade). }\end{array}$ & $\begin{array}{l}\text { Specify rules and conditions for applying for and receiving change in grade } \\
\text { and receiving awards and special treatment associated with each grade. }\end{array}$ & SEC \\
\hline
\end{tabular}


Table 2. Energy Conservation Policy Documents (Central Government), 1981-1990 (continued)

1987 Regarding certain provisions for further strengthening electricity savings.

1989 Certain provisions regarding the work of energy conservation service centers.

1989 Strictly limit the construction of small condensing [thermal] power plants.

1989 Certain provisions regarding encouraging the development of small-scale cogeneration and strictly limiting the construction of small condensing power plants.

1989 Temporary provisions regarding rational utilization of coal and limiting coal consumption.
Encourage adherence to efficiency standards, consumption plans, and other administrative controls over electricity consumption, rapid replacement of inefficient equipment with newer, more efficient models, spread of successful implementation techniques to other areas, increased attention to efficiency of rural power distribution networks, reduction in electricity use in nonproduction sectors, and general improvements in management systems and quality of work. Included absolute limits on unit electricity consumption for production of certain commodities (e.g., $17 \mathrm{MWh} /$ ton and $19 \mathrm{MWh} / \mathrm{ton}$ for electrolytic aluminum production at large- and medium-scale plants respectively).

Set out rules for scope of duties (technical assistance and training, consulting services (e.g., feasibility studies), monitoring, and auditing) and standards for success of energy conservation service centers, of which 200 had been established since 1981.

Restrict construction of small-scale, inefficient power plants, generally built by local authorities to relieve serious local power shortages.

Set guidelines for conditions under which existing heat supply boilers should be converted to cogeneration systems, as well as specifications for the cogeneration systems. Reiterate opposition to local construction of small power plants.

Topics articles address include: more careful use of coal (e.g., closer matching MMat, SPC of coal quality to user needs), efficiency standards, increasing boiler capacities, disseminating efficient boilers, kilns and ovens, encouraging cogeneration and district heating, limiting distribution of coal in winter nonheating zones, and careful monitoring of residential coal distribution.
SC, SPC 
Table 2. Energy Conservation Policy Documents (Central Government), 1981-1990 (continued)

\begin{tabular}{lll} 
Year & Title Purpose/measures \\
\hline
\end{tabular}

Issuing

Authority

1989 Seasonal reporting of energy consumption norms for major products (or amounts of work).

Standardize reporting requirements for unit energy consumption of certain

SSB, SPC coal, refined petroleum, electricity, steel, nonferrous metal, chemical, and light industrial products, as well as unit intensities of vehicle transport.

1990 Temporary provisions for energy conservation monitoring.

Articles cover organization of energy conservation monitoring (to be

N.B. This table excludes numerous policy documents relating to the campaign to convert oil-using equipment to coal.

$\mathrm{ABC}=$ Agricultural Bank of China; $\mathrm{ICBC}=$ Industrial and Commercial Bank of China; $\mathrm{MA}=$ Ministry of Agriculture; $\mathrm{ME}=$ Ministry of Encrgy; $\mathrm{MF}=\mathrm{Ministry}$ of Finance; $\mathrm{MLP}=\mathrm{Ministry}$ of Labor and Personnel; MMach = Ministry of Machinery; MMat = Ministry of Materials; MURCEP = Ministry of Urban and Rural Construction Environmental Protection; MWREP = Ministry of Water Resources and Electric Power; PBC = People's Bank of China; SC = State Council; SEC = State Economic Commission; SPC = State planning Comnission; SSB = State Statistical Bureau.

Source: SPC, 1991. 
In 1986 the State Council also passed a document entitled "Decisions Regarding Problems in Strengthening Management of Industrial Enterprises' Management." This document introduced a plan to rate industrial enterprises according to the quality of their products and the consumption of material inputs - especially energy-per unit of output. The plan thus linked energy conservation with the overall performance of the enterprises. Enterprises were to be divided into four categories: national special, national first, national second, and provincial advanced. These categories were intended to correspond to contemporary international, domestic, and provincial standards from the early 1980. According to these standards, the evaluation of industrial enterprises was first implemented in the machinery, electronic, iron and steel, non-ferrous metals, textiles, petrochemical, and some light industrial sectors. The rating was not to be permanent, but to be revised after periodic evaluations. Based on their rating, enterprises were to receive preferential treatment in the granting of loans, export quotas, increased workers' salaries, and bonuses. This rating system was intended to encourage enterprises to improve their management performance and product qualities and at the same time make energy conservation an indispensable part of successful management.

This rating system was dismantled in 1992 by the SETC, as it was felt to be an unwieldy and expensive way to manage energy use. Some local administrations, e.g., Shanghai, had found the system very effective, however, and continue to implement similar schemes on a local level.

To guide the effective implementation of the energy policy, the State Statistical Bureau and the SPC required the related agencies to collect and report data at least annually regarding physical energy intensities ("Seasonal Reporting of Energy Consumption Norms for Major Products (or Amounts of Work)," 1989). For example, more than 80 intensity indicators were to be collected for about 60 products such as electricity, coal, oil, steel, aluminum, cement, plate glass, ethylene, ammonia, caustic soda, calcium carbide, cotton spinning, and wood pulp. In many cases several intensity indicators referred to a single product, but at different phases of production, in terms of different types of energy used or at different types or scales of plant.

In June 1989, a draft of the "Energy Conservation Law" became available, and since then has undergone numerous changes. It is currently undergoing final revisions before being sent to the State Council for approval, perhaps as early as the spring of 1995. Among the more important rules currently being considered for inclusion are:

- Requiring that all enterprises consuming more than $10 \mathrm{ktce} / \mathrm{yr}$ establish an energy management department staffed by a person who has been certified through a national examination; 6

- Requiring energy audits of inefficient enterprises in five energy-intensive sectors, the enterprises to be chosen based on surveys of the various sectors;

- Requiring that feasibility studies for all new "large" and "medium" scale projects (as defined by the relevant line ministry) include substantive analysis of energy conservation options;

6 The primary difference between this provision and the similar one in the "Temporary Provisions" is the stipulation that personnel be certified at the national level. 
- Continuing a system of energy management through setting energy consumption quotas for enterprises; 7

- Establishing mandatory efficiency standards for consumer appliances, beginning with air conditioners and later including other appliance categories;

- Continuing to make available low-interest loans for energy conservation research, energy conservation demonstration projects, and rural energy demonstration projects.

As disagreement remains overs the content of some of the rules and appropriate means of implementation, the final law may or may not include the above items.

One new dimension of energy conservation in the Seventh FYP was the initiation of building energy conservation aimed at reducing the growing demand for space heating. In July 1987, the SPC and the Ministry of Construction together formulated "Energy Saving Design Standards for Residential Buildings," which specified conservation goals and schedules for implementing improved thermal efficiency standards for heated residential buildings (Chen Min, 1991).

These policies were promulgated and implemented in spite of uncertainties surrounding macroeconomic reform and the slow progress toward the introduction of market mechanisms within the energy sector. Necessity dictated that China implement energy conservation as a means to respond to the challenge of maintaining growth in the face of a slower-than-needed expansion of energy supply.

The existence of centralized institutional structures may have been a necessary condition for the success of the conservation programs. However, the dispersion of authority for investing in energy conservation to local and municipal entities has resulted in lost opportunities to take advantage of potential conservation opportunities across regions. One of the most glaring examples in the power sector is the proliferation of small power plants $(<300 \mathrm{MW})$, which have much lower efficiencies than larger plants and are less likely to incorporate environmental controls (Wirtshafter and Shih, 1990).

\section{Organization and Implementation of Energy Conservation}

A variety of institutions are involved in the development, production, and utilization of energy in China. Development and production fall within the domain of energy ministries and corporations. Because of their high levels of energy consumption, state enterprises also play a key role in the energy institutional structure.

As Figure 2 indicates, to improve the effectiveness of policy implementation, the energy conservation apparatus exists in parallel at the central, ministerial, as well as at the provincial levels. At the local level, more than 200 energy conservation technology centers, with nearly 5000 employees, have been established in ministries and across the country. These centers provide technology consultation, monitoring, and training in energy conservation in the industrial sector for more than 30,000 energy managers.

7 Such quotas are difficult to enforce, since most energy markets are basically free, but they are useful for calculating awards and fines, which some enterprises and local administrations find useful tools in energy management. 
Since the early 1980s China has successfully incorporated energy conservation in the country's institutional structure. Figure 2 lays out the institutional framework for energy conservation activities as it existed in the early 1990s. ${ }^{8}$

The Bureau of Energy Conservation of the SPC was established at the beginning of the Sixth FYP to carry out policymaking and planning for energy conservation. In 1988 it was expanded and renamed the Bureau of Resource Conservation and Integrated Utilization (and later simply the Resources Department). The enlarged administrative body coordinates energy conservation activities among central ministries and local governments; implements resource-development planning and policy, including energy conservation policy; issues regulations and rules for energy conservation; and selects projects and allocates investment funds for projects designated capital construction investments. Local bureaus carry out corresponding activities in their respective regions. Typically commission staff sets conservation policies and targets in association with personnel in energy conservation offices in line ministries and provincial governments, who are more familiar with the details of conservation work within their scopes of authority.

In the early 1980s the Bureau of Energy Conservation of the SPC and the Bureau of Energy of the State Economic Commission (SEC), which was merged with the SPC, and has now been once again separated and reestablished as the State Economic and Trade Commission (SETC), organized energy researchers and experts to analyze energy consumption patterns and conservation potential. Another of the Bureau's tasks was to draw up a national energy conservation plan.

The Office of Energy Conservation Work of the State Council is responsible for selecting and managing energy conservation projects designated technology updating investments. It also arranges for demonstrations of new technologies in pilot projects. ${ }^{9}$ While government attention to energy conservation increased and more administrative bodies were organized to implement policy, coordination of energy conservation planning and project selection became more complicated.

\footnotetext{
8 Energy supply and conservation institutions underwent numerous reforms during the 1980s, but reorganizations were often cosmetic. Often the same people were responsible for roughly the same activities before and after reorganizations. A major difference between Figure 2 and the situation throughout much of the 1980s was the lack of the State Economic and Trade Commission (SETC). Its precursor, the State Economic Commission, was disbanded in the early 1980s.

Under the current system, the State Planning Commission (SPC) and the newly formed SETC will coordination policies across energy subsectors. The SPC will still be responsible for long-term planning, and will also play a role in macroeconomic policy and project selection. One reform, which has been discussed but not fully confirmed, is the merging of the divisions of coal, petroleum, and electricity industries in the Department of Energy; the divisions of energy conservation management, nural, and renewable resources in the old Department of Energy Savings and Comprehensive Resource Utilization, and the Department of Raw Materiais into a "Department of Basic Industries." This department would be committed to the mission described above but specified in the energy sectors.

The SETC's Bureau of Conservation and Integrated Utilization remains responsible for implementing national energy conservation activities, while long-term planning belongs to the SPC.

9 These functions have since been moved to the State Economic and Trade Commission.
} 
Figure 2. Energy Conservation Institutional Framework, 1993

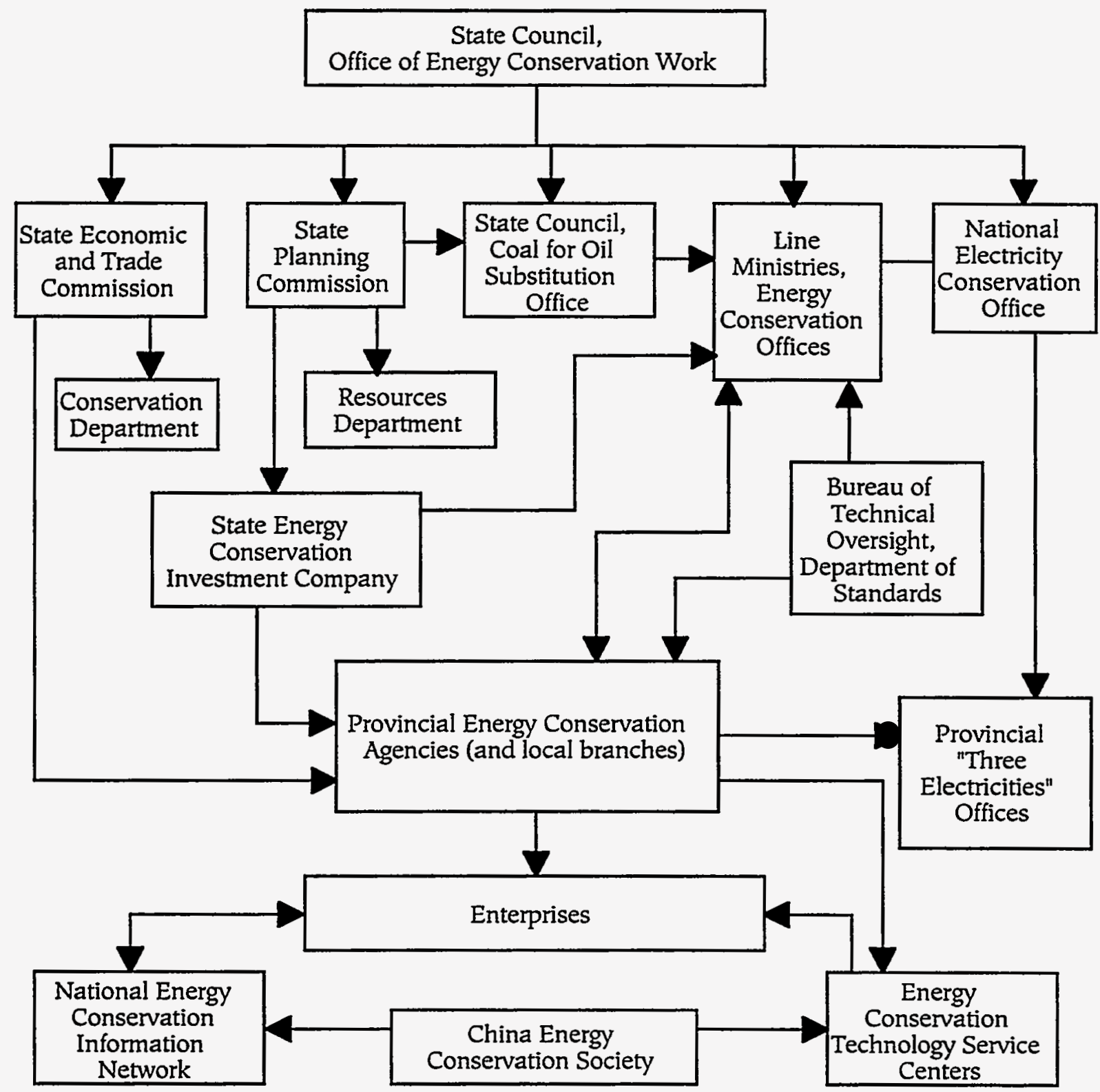

The Ministry of Energy (MOE) was formed in 1988 by consolidating the ministries responsible for various energy supply types. Although its mission was primarily the development of energy supply, it was given a mandate to pursue energy conservation in energy industries as well. The National Electricity Conservation Office, originally located in the Ministry of Water Resources and Electric Power, moved to MOE as well. It was responsible for educational work and transfer of efficient electricity supply and end-use technologies.

In the same year the State Energy Investment Corporation was also established. With a budget allocated by the SPC, this state corporation included a subsidiary responsible solely for conservation investments, the State Energy Conservation Investment Corporation. This latter was the central government's primary vehicle for 
involvement in the program of investments described in this paper, and currently controls a budget of 2 billion yuan per year. ${ }^{10}$ The State Energy Conservation Investment Corporation continues to function as a separate entity, reporting directly to the SPC, while the State Energy Investment Corporation was amalgamated into a new State Development Bank along with several other state investment corporations in early 1994.

Central ministries and local administrations were charged with developing specific regulations on conserving oil, coal, electricity, and water in line with state policies and plans. To date, more than 400 energy standards have been issued for various products and processes, and other actions have been taken as well. The ministries of machinery and electronic equipment, for example, developed and manufactured more than 2000 individual equipment designs that were significantly more energy-efficient than existing equipment, and issued eleven lists of energyintensive products that were to be scrapped. The ministries also recommended sets of energy management techniques and promoted adoption of 13 electricity-saving technologies across the country.

The "Three-Electricities" Bureaus, which are charged with managing rational, safe, and efficient use of electricity, are powerful entities, with branches at provincial, municipal, and county levels. They effectively broker all electricity distribution and sales at the local level, and are seen as key players by Chinese energy conservation officials.

Over 200 energy conservation centers were established in the 1980s. Such centers operate at provincial and municipal levels, as well as within various industries, generally connected to line ministries. These units provide energy monitoring and efficiciency consulting services to enterprises, develop and promote energy conserving technologies, and perfrom feasibility studies. Whereas these centers were formerly primarily funded through the government, in the past few years they have come to rely more heavily on fees charged for services.

The China Energy Conservation Society is an NGO composed of researchers in government units and academia, which provides advice on energy conservation technology and policy, performs feasibility studies. It maintains a National Energy Conservation Information Network, the purpose of which is to promote the exchange of information about various efficient technologies and practices between communities of officials and researchers between whom there is ordinarily little communication. Other NGOs with an interest in energy conservation are the China Energy Research Society, The China Science and Technology Society, and the China Rural Energy Society.

Newspapers and other periodicals, television, radio, and billboards have been used to promote public awareness of the importance of energy conservation. One week each year has been designated as "energy conservation week", when special efforts are made to bring the issue to the attention of the general public.

To ensure that energy conservation work continues, meetings and conferences are held to encourage and monitor energy-savings. efforts. Every December since 1985 the State Council has sponsored an energy conservation working conference. General

10 Currently half of this budget is disbursed as low-interest loans, and the remainder as loans at market interest rates. 
principles and guidelines are issued at these conferences. The actual work of preparing detailed regulations is left to local governments.

There are local governments willing to take the initiative, and sometimes local policy is quite innovative. For example, in Sha City, Hunan Province, a local electricity management office gave a 250,000 yuan loan to the Second Transistor Factory to develop a new energy-saving switch for use in the textile industry. The electricity management office gave the first group of buyers of such switches a $50 \%$ discount as an energy-saving incentive. Even with the $50 \%$ discount however, some enterprises still could not afford switches because of lack of capital. In these cases the electricty management office bought the new switches for the enterprises, but sold the saved electricity to other electricity buyers until the electricity savings had completely compensated the office for the cost of new switches (Huang Ronghua, 1991). This is the first known example of a work unit in China operating as an energy service company, raising funds for energy efficiency investments from the savings that the investments produce.

Impressive as the scope and variety of energy conservation organizations and activities are, attitudes about energy are still biased toward supply. Conservation is seen as desirable in theory but not very workable in practice (Sinton, 1994). It remains difficult to convice enterprise managers, whose main goal has traditionally been to maintain or increase output levels, that the much less visible benefits of energy conservation are worth the trouble. Even in cases where central government funds are made available at excellent terms, end users may refuse to undertake a conservation investment because of a perceived risk or trouble. 11

Other factors weaken support for conservation: the poor reputation of much domestically manufactured equipment, the great expense of imported equipment, and design flaws leading to efficiency decreases instead of increases. Energy efficiency goals have received the same treatment accorded other offically promulgated goals: enterprises endeavor to appear to meet targets, which they try to modify to their own advantage through negotiation, sometimes with the assistance of local authorities.

There is no denying however that in China the goal of energy conservation, with significant momentum behind its implementation, has been institutionalized as in no other nation. In importance to industrial enterprises conservation ranks in the league of environmental protection goals - that is, goals that cannot be safely ignored. No longer promoted solely by the central government, energy conservation has been adopted as an important goal by local governments (the Shanghai municipal government, which holds an energy conservation product trade fair every October, is a notable example). In recent years, as economic system reforms have deepened, local energy conservation centers have been forced to become financially self-reliant. As a result, more of them are aggressively marketing energy-saving devices and services, tailoring their range of products to those that will sell well in an increasingly market-oriented environment. Thus, the institutional structures built up under the central planning system that still existed in the 1980s are providing the basis for organizations that continue to pursue the goal of improving energy efficiency in the very different environment of the 1990s.

11 Plant managers may feel, for instance, that the production lost during the down time needed for installation of a new piece of equipment is more valuable than the benefits of using the new equipment. 


\section{Industrial Energy Conservation Investment Funding12}

Overall investments for conservation projects remained strong through the latter half of the 1980s, though the share of funding declined relative to energy supply. Based on experience in the Sixth FYP and changes in government finances, the central government revised funding mechanisms and selection criteria for energy conservation projects. Direct investments and loans from the central government made up $67 \%$ of total capital construction investment in energy conservation during the Sixth FYP, with local government investment and enterprises' internal funds accounting for the rest (see Table 3). The percentages for technical updating investments were $62 \%$ and $38 \%$, respectively. The central government reduced its share significantly in the Seventh FYP, encouraging enterprises themselves to finance projects. Central and local government and enterprise funds accounted for $51 \%$ and $49 \%$ respectively of capital construction investment and $41 \%$ and $59 \%$ of technical updating investment. According to a 1988

\section{Table 3. Sources of Energy Conservation Investment Funds}

\begin{tabular}{|c|c|c|c|c|c|c|}
\hline \multirow[b]{3}{*}{ period } & \multicolumn{2}{|c|}{$\begin{array}{l}\text { Capital Construction } \\
\text { Investment }\end{array}$} & \multicolumn{2}{|c|}{$\begin{array}{l}\text { Technical Updating } \\
\text { Investment }\end{array}$} & \multicolumn{2}{|c|}{$\begin{array}{l}\text { Total Fixed Capital } \\
\text { Investment }\end{array}$} \\
\hline & central gov't* & local \& & central gov't & local \& & central gov't & local \& \\
\hline & direct loans & enterprise & direct loans & enterprise & direct loans & enterprise \\
\hline
\end{tabular}

A. Million current yuan

6th FYP (1981-1985) 3957

7th FYP (1986-1990) 357

B. Percent

6th FYP (1981-1985) 67\%
1969

54395513

$33 \%$

\begin{abstract}
$1397 \quad 1902 \quad 2002$
\end{abstract}
$0 \quad 1920 \quad 2732$

7256

3971

$357 \quad 7359 \quad 8245$

\section{\begin{tabular}{l} 
7th FYP (1986-1990) $6 \% \quad 45 \% \quad 49 \% \quad 0 \% \quad 41 \%$ \\
\hline Breakdown unavailable for Sixth FYP, estimated for Seventh FYP. \\
Source: Liu Zhiping, ERI, 1993; SPC, 1992; LBL estimates
\end{tabular} \\ \begin{tabular}{lllll} 
7th FYP (1986-1990) & $6 \%$ & $45 \%$ & $49 \% \quad 0 \% \quad 41 \%$ \\
\hline Breakdown unavailable for Sixth FYP, estimated for Seventh FYP.
\end{tabular}}

Source: Liu Zhiping, ERI, 1993; SPC, 1992; LBL estimates

N.B. Coverage and reporting of these data differ from those in Table 1.

12 We do not evaluate rural energy conservation programs in this paper. Building on programs started in the Sixth FYP, the central government continued to promote efficiency improvements in household cooking stoves, firewood planting, biogas digesters, and the small-scale hydropower projects in rural areas. Together these programs were reported to have resulted in the equivalent of a 30 Mtce/year increase in energy supply over the course of the Seventh FYP (Jiang Xianrong, 1989). 
survey of large and medium enterprises, $1348 \%$ of enterprises relied entirely on selfraised funds for energy-related technical updating projects, nearly $8 \%$ relied entirely on government loans, and the remainder relied on both sources. A severe shortage of central governmental capital, and the perception that increasing the proportion of local capital would provide incentive to choose projects with a higher rate of return, lay behind the change. ${ }^{14}$ The central government still directly allocated funds to technical demonstration projects with great potential for national distribution.

The type of central government support for energy conservation also changed. Most state investment came in the form of loans; in the Seventh FYP direct government investment in capital construction projects declined (see Figure 3) and investment in technology updating projects ceased entirely. Typical interest rates for energy conservation investments in the Seventh FYP were 7-8\% for capital construction projects and $3 \%$ or below for technical updating projects. The shares of loans and enterpriseraised funds varied somewhat across industries and years. In 1988 for example, the share of loans in technical updating investments ranged from $35 \%$ in light industry to $69 \%$ in pharmaceuticals (in 1989 the percentages were $32 \%$ and $43 \%$ ).

Figure 3. Share of Direct Investment in Central Government Capital Construction Investment in Energy Conservation

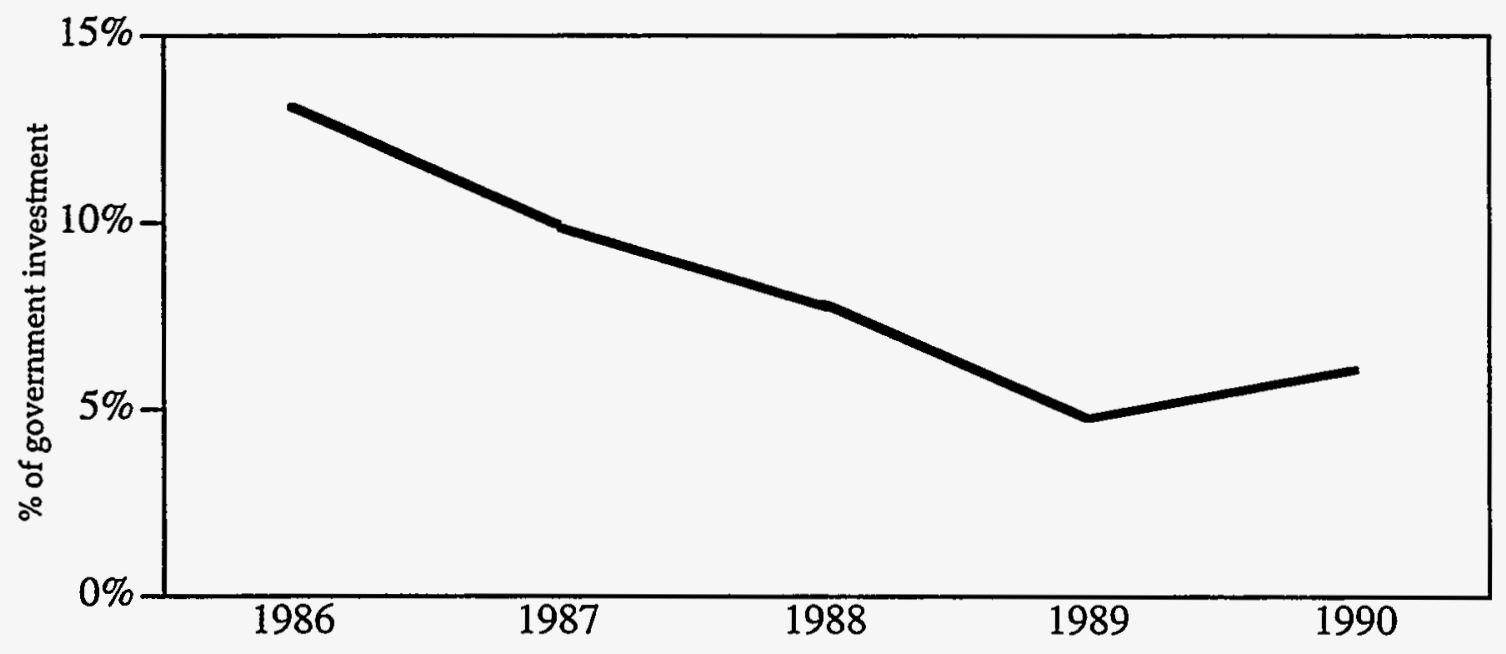

Source: SPC, 1992.

13 CERS, 1989, and He Xuesheng, 1991. The results were based on 1383 completed questionnaires, representing $14 \%$ of large and medium enterprises in that year.

14 The State Energy Conservation Investment Company received applications for projects that were passsed on from enterprises and local administrations through line ministries. Many projects thus originated at the local level, as line ministries solicited applications for conservation funds from enterprises under their administration. 
Some energy conservation projects were re-categorized. Continuous casting and rolling investments, for instance, were now considered as non-energy conservation technical updating projects, rather than energy conservation capital construction projects as in the Sixth FYP, because the primary focus was felt to be expansion of production capacity. Steel scrap processing was reclassified as material recovery. Energy conservation projects aimed at harnessing waste heat and pressure for power generation-previously considered capital construction projects-were reclassified as technical updating. Shifting classifications are in part responsible for the changes in overall gross unit investment (GUI) and other indicators between the Sixth and Seventh FYP periods.

While those responsible for project selection were instructed to incorporate other social objectives into their decisions, no formal criteria were issued. In the end, environmental and other factors were incorporated into the decision-making process in a qualitative and individualistic manner. 


\section{Case Studies of Energy Conservation Investments by Industry}

Energy savings as inferred from macroeconomic data are impressive. During the Seventh FYP the industrial gross output value (GOV) and energy consumption grew at annual rates of $12 \%$ and $5.6 \%$ respectively, and the average energy intensity of China's industrial GOV decreased 5.6\% per year from 530 to $400 \mathrm{kgce}$ per 1000 yuan in 1985 and 1990 respectively (see Table 4). ${ }^{15}$ The net energy conserved in the industrial sector over the period totaled $608 \mathrm{Mtce}$, i.e., the actual amount of energy consumed was $608 \mathrm{Mtce}$ less than would have been consumed had energy per unit of output value remained constant. ${ }^{16}$ Net savings in the metals manufacturing, chemicals, and building materials subsectors together accounted for about half of this total.

How much of these inferred net savings can be attributed to the program of energy conservation investments? ${ }^{17}$ The incompletely reported savings from the programs described below account for $12 \mathrm{Mtce}^{18}$, or $2 \%$ of cumulative savings (608 Mtce) from 1986 to 1990, but this represents only a portion of savings resulting from the program. Assuming the entire reported $24 \mathrm{Mtce} /$ year of savings capacity resulting from all conservation investment programs in the Seventh FYP was operational in 1990, it would have accounted for $11 \%$ of the net 210 Mtce savings in that year (compared to 1985). This might be considered a lower bound for the fraction of the decline in industrial sector energy intensity due to efficiency improvements, since efficiency improvements from installation of new equipment and retrofits not tied to any conservation programs undoubtedly contributed further to intensity decline.

\section{Ferrous Metals Manufacturing Subsector}

The iron and steel industry accounted for roughly $16 \%$ of the $626 \mathrm{Mtce}$ total end use in industry in 1990. This figure does not include energy consumed in the production of more than $3 \mathrm{Mt}$ of steel that was accounted for in other subsectors (total steel production was $67 \mathrm{Mt}$; MOM, 1991). Oil accounted for only about $5 \%$ of subsectoral end use in the latter half of the 1980s, while coal and coal products accounted for 65 to $70 \%$. Fuel-switching and efficiency measures have prevented oil from growing in importance, as in the steel industries in other countries. Oil injections to blast furnaces, for instance, have been replaced entirely by coal powder injections, and some oil-fired boilers have been switched to coal. The use of oxygen injection in open hearth furnaces (pinglu chuiyang) and emulsion combustion technology have also reduced oil

\footnotetext{
15 Energy consumption and output value data used to calculate energy savings are from the Energy Research Institute. GOV data are in constant 1980 yuan.

16 The figure represents net energy saved because, for instance, some changes in industrial structure resulted in increases in intensity (Sinton and Levine, forthcoming), and it is known that in some cases physical intensities increased, or the output shares of factories with higher than average intensities rose. Chinese statistical sources sometimes report energy savings calculated using a rolling base year. By this method accumulated savings in the Seventh FYP were 175 Mice. Unless otherwise stated, all energy savings calculated in this paper are cumulative over the Seventh FYP period, using 1985 as the base year, which was the method of reporting savings from individual projects that the SPC asked to be used in evaluations.

17 Other work suggests that reductions in the physical energy intensity of the sort resulting from conservation investments were responsible for a large share of the drop in economic intensity in the late 1980s (Sinton and Levine, forthcoming; Lin Xiannuan, 1992; Huang Jinping, 1993).

18 Estimated based on incompletely reported energy savings capacity and cumulative energy savings figures. Incomplete reporting, and the liklihood of errors in reporting energy savings and savings capacities require that we view the results below as indicative only.
} 
consumption and increased the overall energy efficiency of production. From 1985 to 1990, the annual growth rates of subsectoral GOV averaged $9.3 \%$ and that of energy consumption averaged $7.1 \%$. The subsectoral energy intensity thus declined at a rate of $2.0 \%$ per year, which led to cumulative macroeconomic savings of nearly 36 Mtce compared to 1985 intensity.

Conservation programs during the Seventh FYP contributed to reducing the energy intensity of iron and steel production from $1.75 \mathrm{tce} /$ ton in 1985 to 1.61 tce/ton in 1990, an annual drop of $1.6 \%$ (see Table 5). In 1990 the comprehensive energy intensity at key state-owned plants was $1.2 \mathrm{tce} /$ ton (MOM, 1992). Major processes in Chinese plants are still less efficient than in plants in developed countries, and efficiency lags are $5 \%-15 \%$ in coking, sterling, ironmaking, and open hearth processes, $30 \%-40 \%$ in converters and electrical furnaces, $15 \%$ in primary rolling, and $30 \%$ in hot rolling (Wang Jianli, 1991). Energy savings from physical intensity drops in the ferrous metals manufacturing industry reportedly totalled 7 Mtce during the Seventh FYP (Yin Ruiyu, 1991).

Conservation projects offered important multiple benefits. Of the nearly $20 \mathrm{Mt}$ increase in steel production experienced during the Seventh FYP, 7.8 Mt resulted from energy conservation investments that simultaneously increased production capacity. Gross investment in technology updating and transformation projects totaled 2 billion yuan, accounting for 2.9 Mtce of conserved energy (MOM, date unknown). The following types of technology updating and transformation projects were undertaken in the Seventh FYP:

(1) Power generation using top pressure in blast furnaces (gaolu dingyacha fadian). Six sets of power generators utilizing top pressure in blast furnaces were installed in four separate steel plants during this period. These generators have a combined capacity of $38.5 \mathrm{MW}$ and generate 230 million kWh annually (Yin Ruiyu, 1991). Four of the six generators were designed and produced domestically. The domestically designed 4.5 MW generator at Jiuquan Iron and Steel (Gansu Province) operates about as efficiently as top pressure power generators of developed countries in the early 1980s (Yin Ruiyu, 1991).

(2) Substitution of coal powder injections for coke in blast furnaces The substitution of coal powder injections for coke in ironmaking is a common practice around the world. During the Seventh FYP, ten projects of this type were carried out in China. By the end of $1990,78 \%$ of key state-run plants and $50 \%$ of local plants used injected coal powder instead of coking coal. The average rate of coal powder use across the industry was $53 \mathrm{~kg}$ coal powder per ton of iron produced. Beijing's Capital Iron and Steel (Shougang) was particularly successful in this program, averaging $120 \mathrm{~kg}$ coal powder per ton of iron (Wu and Meng, 1991). A few additional plants were chosen to demonstrate oxygen-rich coal powder injection methods in ironmaking. Data from the Anshan Iron and Steel in Liaoning Province show that when the oxygen content of combustion air is raised from $21 \%$ to $27 \%$, the amount of coal powder injected into the blast furnace must increase from 73 to $173 \mathrm{~kg}$ per ton of iron produced. Augmented oxygen content and added coal powder raise blast furnace temperatures and increase the amount of iron extracted from ore. The data suggest that increasing oxygen content by $1 \%$ and coal powder injected by 12 to $13 \mathrm{~kg}$ per ton of ore can increase iron production by $2-3 \%$ (Shi Yuexun, 1991). 
Table 4. Economic Energy Intensities and Apparent Net Energy Savings

\begin{tabular}{|c|c|c|c|c|}
\hline & $\begin{array}{l}\text { Energy } \\
\text { End-Use } \\
\text { (Mtce) }\end{array}$ & $\begin{array}{l}\text { Gross } \\
\text { Output } \\
\text { (billion } \\
1980 \text { yuan) }\end{array}$ & $\begin{array}{l}\text { Energy } \\
\text { Intensity } \\
\text { (kgce/yuan) }\end{array}$ & $\begin{array}{l}\text { Energy } \\
\text { Savings } \\
\text { (base year } \\
=1985 \text { ) }\end{array}$ \\
\hline \multicolumn{5}{|c|}{ 1. Industrial Sector } \\
\hline$\overline{1985}$ & 477 & 896 & 0.53 & \\
\hline 1986 & 510 & 987 & 0.52 & 15 \\
\hline 1987 & 553 & 1,147 & 0.48 & 58 \\
\hline 1988 & 593 & 1,383 & 0.43 & 143 \\
\hline 1989 & 620 & 1,506 & 0.41 & 182 \\
\hline 1990 & 626 & 1,570 & 0.40 & 210 \\
\hline sum & - & - & - & 608 \\
\hline
\end{tabular}

2. Ferrous Metals Manufacturing Subsector

\begin{tabular}{lrrrr}
\hline 1985 & 73 & 44 & 1.67 & - \\
1986 & 84 & 50 & 1.67 & 0.2 \\
1987 & 88 & 56 & 1.59 & 4.8 \\
1988 & 94 & 61 & 1.53 & 8.8 \\
1989 & 99 & 65 & 1.51 & 10.9 \\
1990 & 103 & 69 & 1.51 & 11.2 \\
sum & - & - & - & 35.9 \\
\hline
\end{tabular}

3. Nonferrous Metals Manufacturing Subsector

\begin{tabular}{lcccc}
\hline 1985 & 14 & 19 & 0.71 & - \\
1986 & 15 & 21 & 0.69 & 0.3 \\
1987 & 15 & 24 & 0.65 & 1.3 \\
1988 & 17 & 26 & 0.64 & 1.6 \\
1989 & 18 & 29 & 0.63 & 2.2 \\
1990 & 19 & 30 & 0.64 & 2.1 \\
sum & - & - & - & 7.5 \\
\hline
\end{tabular}

4. Chemicals Manufacturing Subsector

\begin{tabular}{lrrrr}
\hline 1985 & 79 & 57 & 1.40 & - \\
1986 & 85 & 62 & 1.37 & 2 \\
1987 & 96 & 74 & 1.29 & 8 \\
1988 & 101 & 89 & 1.13 & 24 \\
1989 & 107 & 98 & 1.10 & 29 \\
1990 & 107 & 107 & 1.00 & 43 \\
sum & - & - & - & 106 \\
\hline
\end{tabular}

5. Building Materials Manufacturing Subsector

\begin{tabular}{lrrrr}
\hline 1985 & 77 & 49 & 1.57 & - \\
1986 & 85 & 58 & 1.45 & 6.9 \\
1987 & 92 & 69 & 1.33 & 16.4 \\
1988 & 98 & 84 & 1.17 & 33.8 \\
1989 & 100 & 94 & 1.06 & 47.3 \\
1990 & 94 & 91 & 1.04 & 47.6 \\
sum & - & - & - & 152 \\
\hline
\end{tabular}

Source: China Project, EAP, LBL 
Table 5. Physical Energy Intensity of Selected Industrial Products, 1981-1990

\begin{tabular}{|c|c|c|c|c|c|c|c|c|c|c|c|}
\hline Product & Unit & 1981 & 1982 & 1983 & 1984 & 1985 & 1986 & 1987 & 1988 & 1989 & 1990 \\
\hline Electricity, net generation [a] & gce $/ \mathrm{kWh}$ & 442 & 438 & 434 & 432 & 431 & 432 & 432 & 431 & 432 & 427 \\
\hline Raw coal production, electricity use [b] & $\mathrm{kWh} / \mathrm{t}$ & 35.68 & 35.88 & 36.35 & 36.68 & 37.29 & 39.12 & 39.55 & 40.89 & 42.73 & - \\
\hline Crude oil production, electricity use & $\mathrm{kWh} / \mathrm{t}$ & 39.82 & 42.96 & 45.08 & 47.24 & 51.58 & 59.39 & 64.5 & 73.27 & 78.75 & 87.97 \\
\hline Oil refining, total energy use & $\mathrm{kgce} / \mathrm{t}$ & & & & & 143.04 & & & 141.54 & 144.86 & 148.94 \\
\hline Steel, all enterprises, total energy use & tce/t & 1.93 & 1.91 & 1.85 & 1.78 & 1.75 & 1.71 & 1.67 & 1.68 & 1.64 & 1.61 \\
\hline Steel, key enterprises, total energy use & tce $/ t$ & - & - & - & - & 1.30 & - & - & 1.21 & 1.21 & 1.20 \\
\hline Steel, local "backbone" enterprises, total energy use & tce $/ t$ & - & - & - & - & 1.72 & - & - & 1.57 & 1.51 & 1.44 \\
\hline Electrolytic aluminum, total energy use & tce $/ t$ & - & - & - & - & 6.93 & - & - & 7.39 & 7 & 6.92 \\
\hline Electrolytic aluminum, DC use & $\mathrm{MWh} / \mathrm{t}$ & 15.73 & 16.108 & 15.63 & 15.46 & 15.05 & 15.29 & 15.38 & 15.25 & 15.04 & 14.92 \\
\hline Cement clinker, energy use [c] & $\mathrm{kgce} / \mathrm{t}$ & 207.53 & 207.62 & 206.01 & 205.85 & 201.1 & 198.15 & 193.3 & 191.2 & 188.3 & 185.42 \\
\hline Cement, total energy use & $\mathrm{kgce} / \mathrm{t}$ & & & & & 210.4 & 207.59 & 202.29 & 199.82 & 200.43 & 201.03 \\
\hline Cement, electricity use & $\mathrm{kWh} / \mathrm{t}$ & 98.62 & 100 & 100.9 & 102.39 & 103.93 & 105.59 & 106.23 & 107.31 & 108.67 & 109.93 \\
\hline Plate glass, energy use & $\mathrm{kgce} /$ case & 30.67 & 30.55 & 30.1 & 29.88 & 30.76 & 31.04 & 32.66 & 31.56 & 29 & 28.59 \\
\hline Ethylene, large-scale equipment, electricity use & $\mathrm{kWh} / \mathrm{t}$ & - & - & - & - & 541 & - & - & 208 & 208 & 198 \\
\hline Ethylene, use of feedstock oil for cracking & $t / t$ & - & - & - & - & 4.15 & - & - & 3.73 & 3.63 & 3.6 \\
\hline Ammonia, large plants, total energy use & tce/t & 1.44 & 1.42 & 1.40 & 1.39 & 1.37 & 1.41 & 1.38 & 1.42 & 1.37 & 1.34 \\
\hline large plants, natural gas use & $\mathrm{m}^{3} / \mathrm{t}$ & & & & & 1043 & 1049 & 1030 & 1013 & 1066 & 1053 \\
\hline Ammonia, medium plants, total energy use & tce $/ t$ & 2.38 & 2.37 & 2.39 & 2.28 & 2.24 & 2.24 & 2.15 & 2.21 & 2.19 & 2.18 \\
\hline medium plants, coke \& coal use & tce $/ \mathrm{t}$ & 1.32 & 1.31 & 1.30 & 1.28 & 1.28 & 1.26 & 1.35 & 1.30 & 1.19 & 1.24 \\
\hline medium plants, electricity use & $\mathrm{MWh} / \mathrm{t}$ & 1.45 & 1.43 & 1.41 & 1.35 & 1.39 & 1.42 & 1.26 & 1.42 & 1.38 & 1.39 \\
\hline Ammonia, small plants, total energy use & tce $/ \mathrm{t}$ & 2.91 & 2.67 & 2.49 & 2.38 & 2.36 & 2.33 & 2.43 & 2.42 & 2.34 & 2.25 \\
\hline Caustic soda, total energy use & tce $/ t$ & 1.71 & 1.72 & 1.69 & - & 1.58 & 1.58 & 1.51 & 1.54 & 1.51 & 1.52 \\
\hline Calcium carbide, key enterprises, total energy use & tce $/ \mathrm{t}$ & - & - & - & - & 2.03 & - & - & 1.93 & 1.94 & 1.92 \\
\hline Calcium carbide, electricity use & $\mathrm{MWh} / \mathrm{t}$ & 3.56 & 3.52 & 3.48 & 3.45 & 3.47 & 3.47 & 3.42 & 3.32 & 3.47 & 3.45 \\
\hline Cotton spinning, electricity use [d] & $\mathrm{MWh} / \mathrm{t}$ & 1.89 & 1.86 & 1.89 & 1.94 & 1.98 & 1.91 & 1.95 & 1.97 & 20.42 & 2.13 \\
\hline Wood pulp, electricity consumption & $\mathrm{MWh} / \mathrm{t}$ & - & - & - & - & 1.52 & 1.55 & 1.54 & 1.59 & 1.56 & 1.57 \\
\hline
\end{tabular}

\footnotetext{
a] Generation intensity figures include only plants with installed capacity $\geq 6 \mathrm{MW}$.

b] Coal production intensity figures include only centrally-run mines; local mines, including provincial mines, are excluded.

[c] "energy use" appears to refer to fuel consumption within the larger category of "total energy use"

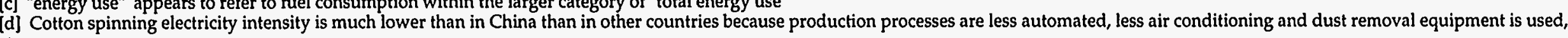

Source: Handbook of Comprehensive Resource Utilization, 1991; China Energy Statistical Yearbook, 1989 \&1991. Zhongguo Nengyuan (China Energy), No. 9, 1993; ERI.
} 
(3) Continuous casting and rolling The capacity of continuous casting and rolling plants doubled over the 7th FYP. By 1990, the ratio of steel produced by continuous casting to the overall total of steel produced exceeded $22 \%$, saving 9.75 million tons of casting billets compared to the replaced technologies. The energy conserved from these projects totaled 1 Mtce over the five-year period-14\% of the total energy conserved in the sector (Li Guitian, 1991).21

(4) Power generation with coal gas recovered from blast furnaces Using coal gasrecovery technology developed in the Sixth FYP, 20 coal gas power generation projects were undertaken in the Seventh FYP. The energy conservation capacity established by the projects totaled $0.3 \mathrm{Mtce} / \mathrm{yr}$ (Xu Derui, forthcoming). However, only $40 \%$ of the recovered coal gas was used to generate electricity. The remainder was used on-site as boiler fuel or off-site as heating and cooking fuel in surrounding residences.

(5) Renovation of boilers and furnaces China's iron and steel industry uses approximately 5000 boilers and furnaces, which consume more than $40 \mathrm{Mtce} / \mathrm{yr}$ (half of the subsector's total energy use). Based on a survey of 300 heating and rolling workshops, industry averages in 1988 were 0.117 tce/ton for furnace energy consumption in hot rolling processes and 0.4 for boiler conversion efficiency (Xu Derui, forthcoming). The energy conservation capacity resulting from boiler-renovation programs totaled 0.4 Mtce/yr (Xu Derui, forthcoming). By the end of 1990, only $10 \%$ of the subsector's boilers and furnaces remained below the performance standards established by the Ministry of Metallurgy.

(6) Coal gas recovery from converters Fourteen companies adopted converter waste coal gas-recovery technology during the 1980s, with the largest projects at Capitol Iron and Steel, Benxi Iron and Steel (Liaoning Province), Anshan Iron and Steel, and Baoshan Iron and Steel (Shanghai). All converters at these plants with volumes greater than 100 tons were retrofitted (Yin, 1991). Seventh FYP investments led to cumulative energy savings of 0.15 Mtce (Xu Derui, forthcoming).

(7) Electricity conservation technologies Severe electricity shortages stimulated interest in development, demonstration, and adoption of electricity conservation technologies. Programs in electricity conservation began in the Sixth FYP and continued in the Seventh FYP with the development of magnetic slot mud (cixing caoni), adjustable-speed drive (ASD) motors, ${ }^{22}$ electric furnace oxygen combustion guns (dianlu yangran qiang), in situ reactive compensation (wugong jiudi buchang), and other technologies. Relatively cheap speed control of AC motors was achieved through use of mechanical hydraulic couplings. The total energy conservation capacity from electricity conservation technologies was $0.12 \mathrm{Mtce} / \mathrm{yr}$ (Xu Derui, forthcoming).

21 These savings do not appear in published statistics on energy conservation programs because continuous casting projects were classified as raw materials utilization projects (not energy conservation projects) in the Seventh FYP despite their significant energy conservation benefits.

22 The speed control mechanism of the adjustable-speed motors was originally developed as a mechanical hydraulic coupler due to its low cost and short payback time. However, electrical hydraulic couplers now being developed promise higher electricity conservation capability. 
(8) Renovation of other processes Numerous processes were renovated in the iron and steel industry. Most plants increased the thickness of sintering materials to $100 \mathrm{~mm}$. Steel rolling operations were moved closer to ingot casting operations, avoiding the need to reheat ingots before rolling. Key state-run plants have adopted hydraulic core rolling and pelling. Anshan Iron and Steel, Baoshan Iron and Steel, and Wuhan Iron and Steel (Hubei Province) adopted heavy oil emulsion combustion technology for their open hearth furnaces and rolling mill heating ovens (Wu and Meng, 1991). Process renovations conserved a total of 0.6 Mtce over the five-year period (Xu Derui, forthcoming).

\section{Non-Ferrous Metals Mining and Manufacturing Subsector}

The annual energy consumption of non-ferrous metal manufacturing increased rapidly in the late 1980s, from less than $15 \mathrm{Mtce} / \mathrm{yr}$ in 1985 to $19 \mathrm{Mtce} / \mathrm{yr}$ in 1990 (see Table 4). The sector's mix of energy sources that year was $56 \%$ electricity, $35 \%$ coke and bituminous coal, 6\% fuel oil, and 3\% LPG and thermal energy. The production of aluminum, copper, lead, and zinc together account for about $80 \%$ of the sector's energy demand (Xiao Zhipeng, 1991).23

For the 1980-1990 period, the annual growth rate for non-ferrous metal manufacturing GOV averaged $9.3 \%$ and that for energy consumption averaged $7.1 \%$. As in the ferrous metals industry, energy intensity declined at a modest rate, $2.1 \%$ per year, leading to cumulative macroeconomic savings of only $7.5 \mathrm{Mtce}$. The most energyintensive metal in the industry, aluminum, barely showed a decline in overall energy use $(0.2 \%$ per year) and only a slightly larger decline in electricity consumption $(0.9 \%$ per year; see Table 5).

Conservation investments totaled 700 million yuan in 800 projects (Fu Shiye, 1991). ${ }^{24}$ These projects, which include both mining and manufacturing activities, resulted in energy conservation capacity of $0.68 \mathrm{Mtce} / \mathrm{yr}$ by the end of the Seventh FYP. Cumulative energy savings from investment projects over the period were over 1 Mtce. ${ }^{25}$

(1) Renovation of processes and equipment at mining sites A variety of conservation measures were used at mining facilities, including development of high-efficiency fans, installation of monitoring and control devices for electromechanical equipment, retrofitting pumps, lifters, and mills, and adoption of large-scale floation processes.

(2) Electricity conservation measures at aluminum plants In an effort to decrease electricity demand, aluminum electrolysis plants adopted several conservation measures during the Seventh FYP. The projects included renovating electrical transformers, increasing electrolyser size, changing electrolyser shape to enhance conductivity, and reducting electrical densities in electrolysers and transmission lines. The Zhengzhou Aluminum Company (Henan Province) increased its electrolyser size

23 The rest of this section also draws on Xiao Zhipeng, 1991.

24 The projects were all classified as technology updating and transformation investments.

25 Details were not available for projects to recover waste heat and pressure in smelting processes. 
and reduced electricity consumption by $700 \mathrm{kWh} /$ ton (typical electicity intensity was nearly $15 \mathrm{MWh} /$ ton in 1990). Some plants added lithium and magnesium compounds to the electrolyte in order to reduce the temperature of electrolysis, reducing electricity consumption by as much as $300-500 \mathrm{kWh} / \mathrm{ton}$.

(3) Advanced technology imports A number of processing plants imported advanced technologies such as high-efficiency kilns in addition to renovating existing equipment. The Zhuzhou Metallurgical Company (Hunan Province) imported an air cooling tower to replace an old vacuum-vapor cooling system in a zinc electrolyte cooling process. Some Bayer process aluminum producers replaced conventional digester processes with imported rectifier units, roasting kilns, and tube digester equipment (guandaohua jinshu zhangbei), reducing the energy consumption of the process by half.

\section{Chemicals Manufacturing Subsector}

Consuming 107 Mtce, 9.1\% of industrial sector energy consumption in 1990, China's chemicals subsector is also a major energy consumer. The chemical fertilizer, basic chemical raw materials, and organic chemical industries account for $90 \%$ of the sector's energy demand.

The energy consumption mix in China's chemical industry differs from that in most other countries, relying on coal for $52 \%$ of energy inputs (including feedstocks) in 1990. Electricity and heat accounted for 32\%; oil and natural gas combined accounted for only $16 \%$. In the chemical industries of developed countries high-grade fossil fuels typically account for the bulk of consumption. In contrast, only 13 chemical plants in China use natural gas and naphtha as raw materials. Typical electricity intensities in 1990 were $1.4 \mathrm{MWh} /$ ton ammonia, 2.7 MWh/ton sodium hydroxide, 3.6 MWh/ton calcium carbide, and $16 \mathrm{MWh}$ /ton yellow phosphorus (see Table 5).

The annual growth rates of subsectoral GOV and energy consumption over the Seventh FYP averaged $13.6 \%$ and $6.2 \%$, respectively. ${ }^{26}$ The economic energy intensity decreased $6.5 \%$ annually resulting in macroeconomic savings of 106 Mtce during the period (see Table 4).

Average annual drops in the physical energy intensity of ammonia were $1.8 \%$ in large-scale plants, $2.7 \%$ in medium-scale plants, and $4.4 \%$ in small-scale plants. The physical energy intensity of sodium hydroxide (at key plants) and calcium carbide declined at annual rates of $4.7 \%$ and $5.4 \%$, respectively.

The chemical industry's technology updating projects in the Seventh FYP built upon the lessons from demonstration projects in the Sixth FYP. Seventh FYP projects concentrated on the recovery of low-temperature waste heat and waste heat from chemical reactions, recovery of fuel gas, renovation of fans and pumps, and cogeneration.

Investments in conservation programs totaled 400 million yuan over the Seventh FYP (with 250 million yuan in the form of low-interest government loans and the rest from other sources such as enterprise internal funds) and resulted in energy conservation capacity of $0.5 \mathrm{Mtce} / \mathrm{yr}$ (Zeng Guangan, 1992). The World Bank also

26 State-owned enterprises only. 
granted a 200 million yuan loan for productivity improvements in large-scale ammonia plants. ${ }^{27}$

The government sponsored the following conservation projects in China's chemical industry during the Seventh FYP:

(1) Renovation of large-scale ammonia plants The Chinese imported 13 sets of ammonia-production facilities during the 1970s. Eight sets use natural gas as the raw material in Kellogg production processes, three sets use naphtha in Todsoe processes, and two use naphtha in advanced Kellogg processes. These plants have consumed $20 \%$ more energy than similar plants abroad. The World Bank loan was used to renovate four of these large-scale plants. Renovation projects focused on improving decarbonizing systems and recovering fuel gases. The projects in large-scale ammonia plants resulted in an energy conservation capacity of $0.15 \mathrm{Mtce} / \mathrm{yr}$.

(2) Renovation of medium-scale ammonia plants Of the more than 60 medium-scale ammonia plants in China, $60 \%$ use coal and coke as raw material. The utilization efficiency of coke and steam in these plants is relatively low. Renovation projects in medium-scale plants focused on retrofitting equipment in synthesis towers (including installation of waste heat boilers), recovering waste heat from chemical reactions, ${ }^{28}$ recovering emitted hydrogen, ${ }^{29}$ applying low-energy-intensity techniques to decarbonizing systems, adopting closed-cycle technologies, and improving heattransfer efficiencies (Dai et al., 1992). Investments for renovations in 13 medium-scale plants totaled 26 million yuan ${ }^{30}$ and resulted in an energy conservation capacity of 0.08 Mtce/yr.

(3) Renovation of small-scale ammonia plants China's 1056 small-scale ammonia plants produce about 12 million tons of ammonia annually, $60 \%$ of the nation's total annual output (1990), and consume a slightly larger share of energy inputs to ammonia production. During the Sixth FYP, 147 small-scale ammonia plants were renovated. Projects primarily involved the recovery of waste gases (blow-by gas, emitted gas, and regenerated gas), equipment retrofits in synthesis towers, closed systems for heating and cooling water, and general equipment improvement and redesign.

During the Seventh FYP, the central government emphasized waste heat recovery and utilization projects. In 1988, the Ministry of the Chemical Industry approved a waste heat recovery project at a small plant in Shouguang county, Shandong Province. Enough waste heat was recovered from production processes to raise steam for all production processes (including carbonization), eliminating the need for primary steam generation. This project is considered to be a model for small-scale plant renovations in the Eighth FYP (Wang Bingxin, 1990).

There were numerous other renovations in small-scale plants during the Seventh FYP. These projects significantly improved productivity in addition to conserving

27 This loan was not limited to energy conservation investments only.

28 This measure, reported to reduce the intensity of ammonia production by $70-85 \mathrm{kgce} / \mathrm{ton}$, has been adopted by more than half of all plants (Dai Yande et al., 1992).

29 The hydrogen content of emitted gas is typically $50-60 \%$.

30 Excluding internal capital. 
energy. Such projects included power generation with recovered waste heat in carbon black and sulfuric acid plants, closed calcium carbide kilns, dry dust removal techniques, and hollow electronic cathodes.

\section{Building Materials Manufacturing Subsector}

In 1990 the building materials industry was China's third largest industrial energy user, consuming $94 \mathrm{Mtce}-15 \%$ of total industrial energy use. The cement, brick, and lime industries together account for $90 \%$ of the subsector's total energy use. Table 6 shows the energy consumption of various building materials industries in 1990.

The use of greatly outdated technology and equipment in the building materials industry contributes to its high energy consumption. Equipment made in the 1970s and 1980 s makes up only a small portion of the operating total. Moreover, the majority of the sector's energy consumption comes from small-scale plants, as in the chemical sector. Small-scale cement plants consume $80 \%$ of the cement subsector's energy demand, and non-state-owned brick plants (usually small-scale) consume $90 \%$ of the brick subsector's energy demand. The mix of energy sources is again characterized by high coal use and low oil use; in 1990 the subsector consumed $78 \%$ coal, $14 \%$ electricity, and $8 \%$ oil.

The annual growth rates of GOV and energy consumption during the Seventh FYP were $13 \%$ and $4.1 \%$, respectively. The subsector's economic energy intensity therefore decreased at an annual average rate of nearly $8 \%$, for cumulative macroeconomic savings of 152 Mtce compared with 1985 intensity (see Table 4).

Over the same period, the physical energy intensity of clinker production at medium-scale cement plants dropped $7.8 \%$ per year, from an average of 201 to 185 $\mathrm{kgce} / \mathrm{ton}$. Overall energy intensity of cement production dropped more slowly at $4.5 \%$ per year, partly because electricity intensity rose steadily as production became more mechanized. Energy intensity at plate glass plants decreased from an average of 30.8 $\mathrm{kgce} /$ case (50 kg glass/case) in 1985 to $28.6 \mathrm{kgce} /$ case in 1990, an annual decrease of more than $7 \%$ (see Table 5).

Table 6. Energy Consumption of Building Materials Industries

\begin{tabular}{lcc} 
Industry & Energy Consumption(Mtce) & Percent of Total \\
\hline & & \\
Bricks & 56.47 & $47.6 \%$ \\
Cement & 40.41 & $34.1 \%$ \\
Lime & 10.49 & $8.8 \%$ \\
Plate Glass & 3.30 & $2.8 \%$ \\
Ceramics & 2.91 & $2.5 \%$ \\
Cement Products & 0.64 & $0.5 \%$ \\
Glass Fibers & 0.51 & $0.4 \%$ \\
\hline
\end{tabular}

N.B.: Total may not agree with Table 4 because of different data sources.

Source: (Wang Gang, 1991) 
Conservation investments in the building materials manufacturing sector during the Sixth and Seventh FYPs totaled one billion yuan with 600 million yuan coming from government loans. ${ }^{31}$ These funds provided for more than 700 energy conservation projects and established a total energy conservation capacity of $2 \mathrm{Mtce} / \mathrm{yr}$. The projects also yielded other significant benefits: 320 million $\mathrm{kWh}$ of electricity generated from recovered waste heat and 10 million additional tons of cement produced (Chen Min, 1991). The same source estimates that conservation investments, exclusive of projects to convert waste heat to electricity, cost less than 400 yuan/tce-yr, and that accounting for productivity improvements would yield a net investment in conservation of about zero. The following are the main projects undertaken within the industry during the Sixth and Seventh FYPs. ${ }^{32}$

(1) Reconstruction of cement kilns The mechanization of conventional vertical kilns 33 was the major project of both the Sixth and Seventh FYPs, requiring more than 300 million yuan of investment, of which two-thirds came from the state and the remainder from enterprises. A total of 165 conventional vertical cement kilns were mechanized, resulting in an energy conservation capacity of $1.5 \mathrm{Mtce} / \mathrm{yr}$. These mechanical kilns increased production capacity by an additional 8.5 million annual tons over the ten-year period.

(2) Electricity generation with waste heat in cement plants Installing electricity generation capacity that utilizes recovered waste heat and renovating existing waste heat generation capacity ${ }^{34}$ were important projects. The installation and renovation of generators allowed most cement plants to provide about $50 \%$ of internal electricity demand, and some plants were able to satisfy $80-90 \%$ of their demand. Investments in electricity generation from waste heat totaled 100 million yuan and added 96 MW of installed generation capacity. 35

(3) Electricity conservation in cement grinding Electricity conservation measures, including the use of phase modifiers and the renovation of the face plates (chenji) of cement grinding plants, were inplemented in ten large and several smaller plants in the mid-1980s. Investments totaling 600 million yuan resulted in the conservation of 200 million $\mathrm{kWh}$ over the period.

(4) Heat-resistant steel chains in wet-process kilns Replacing ordinary steel chains with heat-resistant steel chains in wet-process cement kilns allows materials to be moved closer to the kiln's hot end, thus improving the heat-transfer efficiency of the process. This improvement in heat transfer, in turn, increases production capacity.

31 Information on the ten years from 1981 to 1990 only was available, and the figures in this section refer to that period unless otherwise noted. We include this section nevertheless because similar projects were pursued during both the Sixth and Seventh FYPs.

32 The following information is taken from Chen Min, 1991 unless otherwise noted.

33 See Wang Shumao, 1992, and Liu Feng, forthcoming, for technical details of this type of project.

34 Renovations of existing capacity took the form of upgrading the operating parameters from low-pressure generators to midpressure generators.

35 The cost of providing electricity from waste heat $(1,040 \mathrm{yuan} / \mathrm{kW})$ compares quite favorably to the cost newly constructed coal-fired power plants. 
Twenty large and medium plants made investments totaling 7.6 million yuan in this type of renovation. The investments provided an energy conservation capacity of 30 $\mathrm{Mtce} / \mathrm{yr}$, an average increase in production capacity of $2-3 \%$, and the saving of $5 \mathrm{kt}$ of rolled steel product over the period.

(5) Fluidized layer in cement-drying machines Replacing the conventional combustion chambers of drying machines with a fluidized layer can increase the energy efficiency of the drying process line and decrease coal use by $30 \%$. The renovation of one drying process required only a 300,000 yuan investment with a payback time of less than one year. More than 30 cement plants adopted this measure.

(6) Utilization of stack gases from plate glass smelters The typical temperature of stack gases from plate glass smelters is about $500^{\circ} \mathrm{C}$. The amount of energy released in these gases equals $10-20 \%$ of the smelters' energy input. The recovery of stack gases could thus provide significant quantities of useful steam for both production processes and household use in surrounding residences. During the ten-year period, 25 enterprises invested 9 million yuan to install stack gas recovery equipment and waste heat boilers. The Hangzhou Glass Company (Zhejiang Province) installed three waste heat boilers and recovered nearly $4.4 \mathrm{Mtce}$ of heat over the period.

(7) Refractory and insulating materials in plate glass smelters The use of refractory and insulation materials in the pool walls, heat storage chambers, and other parts of plate glass smelters can reduce the energy consumption of glass production by $15-20 \%$. The Weihai Glass Plant (Shandong Province), for example, improved the insulation of their smelter and conserved $6 \mathrm{kt}$ of coal over the ten-year period. The Qinhuangdao Glass Company (Hebei Province) reduced the heat loss in their kiln so that its energy consumption was only $7.1 \mathrm{MJ} / \mathrm{kg}$-quite low compared to glass kilns worldwide.

(8) Utilization of waste heat in brick tunnels and rotating kilns With investments totaling 20 million yuan, 93 brick plants constructed drying chambers and tunnels to use recovered waste heat from kilns to dry primary brick products. In some cases these projects allowed plants to extend operations into times of year when air-drying bricks would be impractical.

(9) Demonstration projects to improve the performance of mechanical kilns At the beginning of the Seventh FYP, the SPC and the Administration of Building Materials chose the Tuxian and Wuping Cement Plants (in Anhui and Shandong Provinces) as demonstration sites for advanced technological renovations in mechanical cement kilns. At Tuxian, the renovations included reconstruction and insulation of the kiln body, decreased temperatures in the brick-forming process, electricity conservation measures, installation of computer control systems for raw material mixing, monitoring and adjusting combustion parameters, and improved product quality and variety. These renovations reduced energy intensity from 160 to $120 \mathrm{kgce} /$ ton clinker and electricity 
intensity to $80 \mathrm{kWh} /$ ton. ${ }^{36}$ The two projects produced an average energy conservation capacity of $3.6 \mathrm{Mtce} / \mathrm{yr}$ and production capacity increases of $10 \mathrm{kt} / \mathrm{yr}$. Based on plant statistics, project investments totaled 1.24 million yuan while savings resulting from the projects totaled 1.2 million yuan/yr, allowing a payback time of approximately one year (Anon., 1989). These demonstration projects were intended to serve as blueprints for similar renovation programs in the Eighth FYP.

36 Intensities of mechanical kilns (which produce $60 \%$ of China's cement) range from 110 to $225 \mathrm{kgce} /$ ton clinker, with an average of $165 \mathrm{kgce} / \mathrm{ton}$ clinker in 1990 (Liu Feng, forthcoming). Typical pre-renovation electricity intensity is $87 \mathrm{kWh} / \mathrm{ton}$ cement. 


\section{Economic Evaluation of Investments}

Table 7 shows how the project types considered in this section roughly map onto the industrial sectors. We treat conservation investment project categories that cross subsectoral divisions, i.e., the categories by which the central government classifies its investment projects. We first set out a simple method for calculating investment cost and note the weaknesses in the data set underlying our analysis. Then we consider projects that fall into the categories of capital construction and technical updating and transformation.

\section{Analytic Methodology: Gross and Net Unit Investment}

The SPC has published some data on the results of state-sponsored energy conservation investments in industry (SPC, 1991). Investment funds and the resulting commodity production and energy conservation capacities are reported by time period (year or FYP period), investment category (capital construction or technical updating and transformation, ${ }^{29}$ ) industrial subsector, project type (e.g., cogeneration or manufacturing briquettes), and region. 30 While the data are reported in a fashion that makes comparisons between investments difficult, we feel that by using a simple methodology and stating explicitly the data problems we can build a rough but informative picture of the results of the investment programs. The central government's basic criterium for investing in energy conservation projects was that energy conservation supply be cheaper than new energy supply. In most cases the yardstick was coal, the cost of which was estimated to be 500 yuan per annual ton of delivered coal (including 300 yuan for extraction and 200 yuan for transportation facilities) in the Sixth FYP (Huang Yicheng, 1989) and 1000 yuan per annual ton in the Seventh FYP (ERI estimate).

We prepared indicators on gross unit investment (GUI) by FYP for all project types and on net unit investment (NUI) where the necessary information was available. GUI is the amount of funds needed to build one unit of energy savings capacity 31 taking the entire investment as directed solely at energy savings. NUI recognizes that these projects typically had multiple benefits and attempts to account for one aspect of those multiple benefits, i.e., production capacity expansion. NUI is calculated by subtracting from total investment that portion that would have been necessary to achieve an equal increment in production capacity through construction of a reasonable alternative facility and calculating unit investment in energy conservation capacity with the remainder (Liu Zhiping, 1987). Since investments in new production capacity can be substantial, NUIs are often negative. GUI and NUI are defined as follows:

\footnotetext{
29 Capital construction investment generally refers to new capacity construction and expansion projects, as well as purchases and installation of equipment that result in net additions to productive capacity. Technical updating and transformation investments are generally intended for the repair and renovation of existing plants. Projects are not primarily intended to expand capacity but often do in practice.

30 Data by investment category are more complete than those reported by subsector.

31 Energy savings capacity is defined in terms of savings relative to intensity in a base year. For the Sixth FYP (1981-1985) the base year is 1980 and for the Seventh FYP (1986-1990) the base year is 1985.
} 


$$
\begin{aligned}
& G U I=\frac{I_{c}}{E S C} \\
& N U I=\frac{I_{c}-\left(i_{a l_{r}} \times \Delta Q\right)}{E S C}
\end{aligned}
$$

where:

$I_{c} \quad=\quad$ total investment in conservation investment project(s),

$E S C=$ energy savings capacity resulting from investment projects,

$i_{\text {alt }}=$ unit investment in alternative new production capacity, and

$\Delta Q=$ change in production capacity in plants from conservation projects.

Table 8 provides information on $i_{\text {alt }}$ and $\Delta Q$ needed for rough estimates of $N U I$.

No effort is made to take project lifetime and operating costs into account. While this would not be sensible from the point of view of a Western investor, investors in China typically consider only up-front costs in making investment decisions. The ranking of investments according to GUI and NUI gives a fair idea of how the various projects would seem from the point of view of Chinese investors. 
Table 7. Energy Conservation Projects by Industrial Subsector, Seventh Five-Year Plan (a)

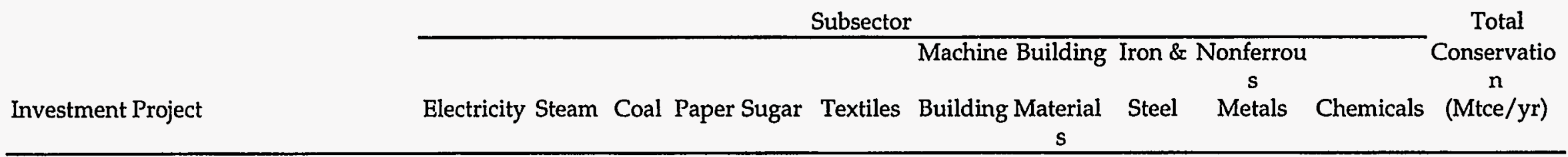

Capital Construction

Cogeneration

Small Generator Replacẹment

Small Fertilizer Plant Renovation

Small Cement Plant Reriovation

Fuel-Gas Recovery

District Heating .

Honeycomb Briquettes

Coal Processing

Raw Material Conservation (b)

Technology Updating

Waste Heat \& Pressure Utilization

Boiler and Heat Supply Retrofits

Furnace \& Kiln Retrofit

Process Renovation (various).

Equipment Renovation (various) (b)

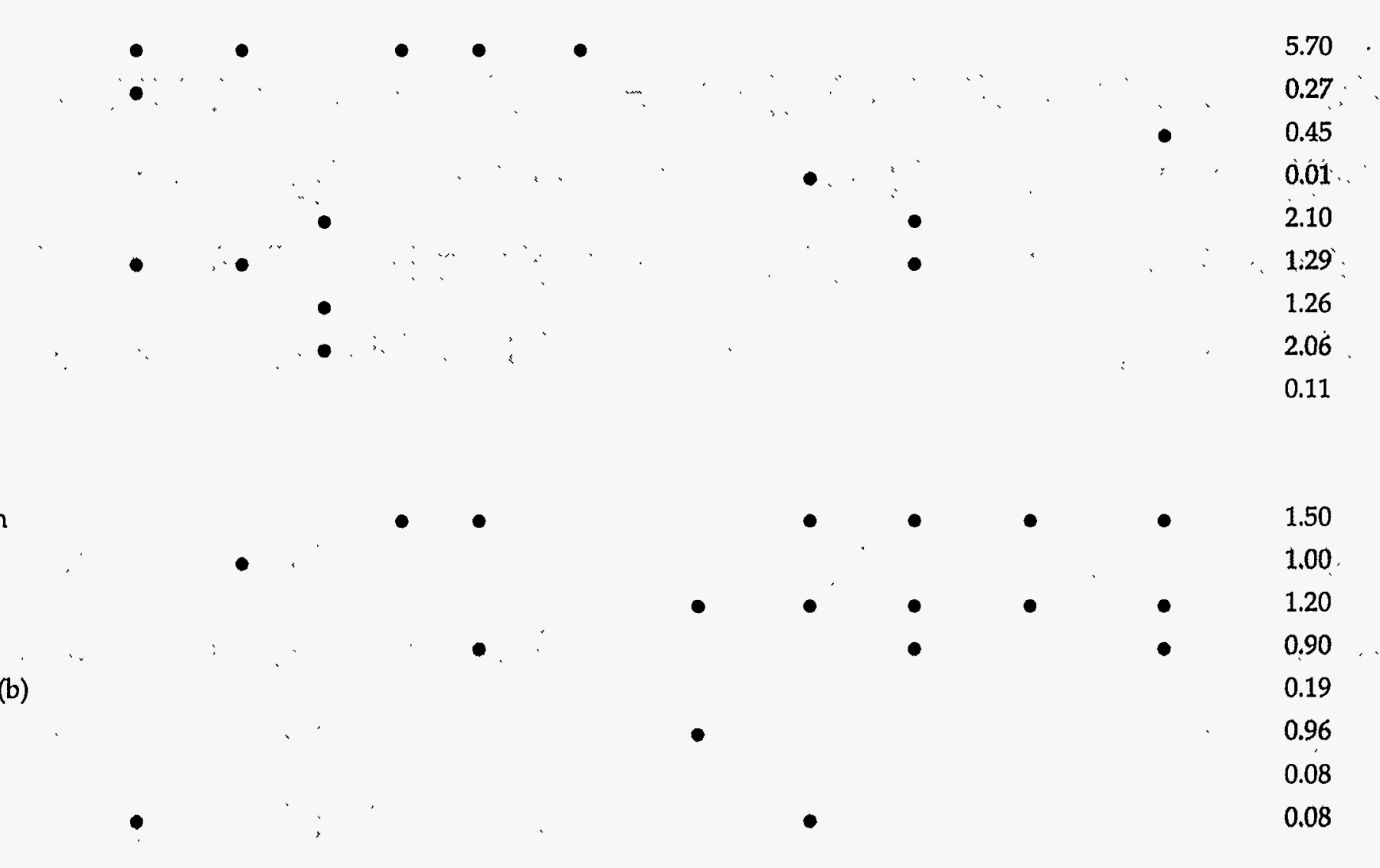

High-Efficiency Equipment

Matching Coal to End-Use (b)

CMT Utilization

(a) Information presented in this table may be incomplete.

(b) Industry-specific information unavailable. 
Table 8. Unit Investment, Alternatives to Capital Construction Projects (1986-1990)

\begin{tabular}{|c|c|c|}
\hline $\begin{array}{l}\text { Capital Construction } \\
\text { Energy Conservation Project }\end{array}$ & $\begin{array}{l}\text { Alternative } \\
\text { Project }\end{array}$ & $\begin{array}{l}\text { Unit } \\
\text { Investment }\end{array}$ \\
\hline Cogeneration & $\begin{array}{l}\text { conventional heat and power } \\
\text { generation }\end{array}$ & $\begin{array}{l}150,000 \text { yuan } / \\
\text { (t-steam } / \mathrm{hr} \text { ) } \\
2000 \text { yuan } / \mathrm{kW}\end{array}$ \\
\hline Small Power Plant Replacement & conventional power generation & 2000 yruan $/ \mathrm{kW}$ \\
\hline Small-Scale Fertilizer Plants & medium-scale fertilizer plant & $\begin{array}{l}829 \\
\text { yuan/(ton/yr) }\end{array}$ \\
\hline Small-Scale Cement Plants & medium-scale cement plant & $\begin{array}{l}400 \\
\text { yuan } /(\operatorname{ton} / \mathrm{yr})\end{array}$ \\
\hline Fuel-Gas Recovery & coal-gas supply and distribution & $\begin{array}{l}55 \\
\text { yuan } /(\mathrm{tcm} / \mathrm{yr})\end{array}$ \\
\hline District Heating & $\begin{array}{l}\text { dispersed boilers and household } \\
\text { stoves }\end{array}$ & 40 yuan $/ \mathrm{m}^{2}$ \\
\hline Honeycomb Briquette & hand-shaping of briquettes (labor) & 20 yuan/ton \\
\hline Coal Processing & no processing & - \\
\hline Raw Materials Savings & conventional systems & - \\
\hline \multicolumn{3}{|l|}{$\begin{array}{l}\text { Technical Updating } \\
\text { Energy Conservation Project }\end{array}$} \\
\hline Waste Heat \& Pressure Recovery [a] & small cogeneration plant & 1600 yuan $/ \mathrm{kW}$ \\
\hline Boiler \& Heating System Retrofits & conventional heat supply & $\begin{array}{l}150,000 \text { yuan/ } \\
\text { (t-steam/hr) }\end{array}$ \\
\hline Industrial Fumace \& Kiln Retrofits & conventional systems & - \\
\hline Industrial Process Renovation (various) & conventional processes & - \\
\hline $\begin{array}{l}\text { Industrial Equipment Renovation } \\
\text { (various) }\end{array}$ & conventional equipment & - \\
\hline High-Efficiency Equipment Design \& Mfg & conventional equipment & - \\
\hline $\begin{array}{l}\text { Mixing Coal to Utility Boiler } \\
\text { Specifications }\end{array}$ & no mixing & - \\
\hline \multicolumn{3}{|l|}{$\begin{array}{l}\text { Specifications } \\
\text { Coal Mine Tailing Utilization }\end{array}$} \\
\hline
\end{tabular}

tcm $=$ thousand cubic meters

[a] Reported in Rational Resource Utilization Handbook.

Source: ERI.

\section{Uncertainties in Conservation Investment and Energy Savings Data}

The data on which this section is based are weak in some respects, limiting the strength of the conclusions drawn from them. Investment data by type of project are available only as totals, in current yuan, for the FYP periods. The aggregation of five years of investments by project type in current yuan results in an unknown amount of inflation in the totals, overstating the cost of the conservation projects, especially in the Seventh FYP. An attempt might be made to approximate real investment by dividing up the total investment among the various years and applying appropriate deflators (like the 
ones used to deflate total conservation investment figures), but the result would be arbitrary and of uncertain value. ${ }^{1}$

Data on energy savings capacities by type of project are also presented as sums for the FYP periods. The reported "completed" and "planned" energy savings capacity figures highlight the difficulties introduced by aggregating investment data. Many projects take several years to complete, requiring continued investment before coming on line. Reported investment, then, is often greater than that needed to install "completed" capacity, and less than that required for "planned" capacity. Some of the GUI figures based on completed and planned capacity are identical, but for the Seventh FYP the former is sometimes 10 to 20 times the latter, reflecting a large amount of capital tied up in incomplete projects. Separately reporting investments in completed and incomplete projects would help clarify analysis of unit costs.

Although annual data for the various project categories would enable improved analysis, further difficulties would remain. In particular, projects differ greatly even within the same project type category. Some waste gas recovery projects, for instance, include construction of gas distribution networks-a major portion of the total cost of the project-whereas others simply feed gas into an existing distribution system. As another example, without detailed information on the projects that replaced small condensing generators with higher performance units, meaningful economic evaluation is not feasible. Project categories that appear to be cost-effective overall may contain many examples of excessively expensive individual projects, and vice versa. Calculation of NUI becomes even more problematic, since a collection of projects each exhibiting different features can hardly be compared to a single alternative.

The figures on energy savings capacity are further subject to some uncertainty. The reporting units were asked to submit information on energy savings capacity, rather than the basic data from which it could be calculated. Uniform criteria on calculating energy savings capacity were not applied, so savings capacities of various projects may not be comparable. Moreover, enterprises have been subject to incentives to under- or over-report energy savings. Especially in the early stages of reform, reporting of large savings may have aided some managers in receiving promotions or preferential treatment for their enterprises. The desire to maximize allocations (based in part on energy consumption in the previous year) of energy products at cheap in-plan prices, however, may have caused some managers to understate savings. (This may no longer be a factor now that energy prices are being substantially liberalized, but it would have been important in the 1980s.) Savings are furthermore reported in terms of coal equivalent and occasionally in terms of electricity. In some cases the appropriate alternative project type is reasonably clear, but in the cases where it is not clear, we can only compare energy savings to the cost of new coal supply. The degree to which the foregoing factors affect the aggregate savings figures is unknown.

Under these circumstances, accurate evaluation of investment costs is difficult. The best that can be done is to put rough bounds on what the actual costs were, given currently available data. GUI may be considered an upper bound to unit project cost, if conservation project lifetimes are assumed to be comparable to alternatives. This may

\footnotetext{
1 A weak check could be made (but only for the technical renovation project category) by comparing the annual totals of assigned investment figures with the actual investment totals. which are available by year.
} 
be an unwarranted assumption in many cases however, since conservation projects often involve retrofits to existing equipment, which is unlikely to remain in service for as much time as newly built energy supply or commodity production capacity. A more reasonable upper bound then might lie somewhere above the GUI figures calculated here. NUI gives what might be considered a lower bound to unit cost, especially given the problem of different lifetimes. The often negative values for NUI found below should be treated carefully; while it is difficult to accept that investors were in effect paid to undertake conservation measures, the difference between GUI and NUI highlights the multiple incentives from the social perspective to make these investments. The direction and magnitude of this difference may be taken as a measure of confidence in our use of GUI as an upper bound.

We regard the unit investment figures presented below as preliminary only. They provide an approximate ranking of alternatives, a ranking that would probably be revised were more detailed data to become available. We nevertheless believe that the overall impression gained from the following, i.e., that energy savings were on average far cheaper than new energy supply in the 1980s, would be substantiated by an investigation deeper than the one possible here.

Better evaluation of energy conservation investments, key to improving performace of the overall energy conservation investment program, will require a considerably more detailed data set than that currently available. Analyses that take into account project lifetimes, operating costs, and qualitative differences among alternative projects will probably become more necessary in the future, in part because economic and enterprise reforms will encourage enterprises to consider more carefully the economic consequences of investment decisions, and in part in response to the needs of the increasing number of foreign investors in China's industrial and other sectors. For overall characterization of investment projects, analysis of aggregate data is unsatisfactory. Future work should focus on developing indicators (e.g., cost of conserved energy) separately for each project, or for groups of projects similar in terms of lifetime and alternative. Some of the needed additions and improvements to the data set include:

- investment by project and year (to enable appropriate deflation)

- linking of investments to project capacities and completion dates

- project lifetimes

- project descriptions detailed enough to determine appropriate alternative projects and to enable assignment of costs to energy conservation and other improvements

- estimated project operating costs.

While gathering detailed information on every conservation project is probably not feasible, close analysis of representative samples of different project types would provide a firmer basis for targeting future investments.

\section{Capital Construction Investments}

Investments in capital construction projects in the Seventh FYP increased by about half in real terms over the Sixth FYP. Nearly $15 \mathrm{Mtce} / \mathrm{yr}$ of energy conservation capacity 
resulted from Seventh FYP capital construction energy conservation projects (see Table 9). Almost two-thirds of that conservation capacity came from cogeneration, fuel gas emissions recovery, and district heating projects (see Table 10). Details about investments are laid out in the sections following the tables.

\section{Table 9. Capital Construction Investment in Energy Conservation, 1981-1990}

\begin{tabular}{|c|c|c|c|c|}
\hline Year & $\begin{array}{l}\text { CC } \\
\text { Investment } \\
\text { (million } \\
1980 \text { yuan) }\end{array}$ & $\begin{array}{l}\text { Fraction of } \\
\text { Total } \\
\text { Conservation } \\
\text { Investment }\end{array}$ & $\begin{array}{l}\text { Total } \\
\text { Energy Savings } \\
\text { Capacity } \\
\text { (Mtce/year) }\end{array}$ & $\begin{array}{l}\text { Unit Cost } \\
\text { of Energy } \\
\text { Savings } \\
\text { (1980 yuan/ } \\
\text { (tce/yr)) }\end{array}$ \\
\hline 1981 & 591 & $40 \%$ & - & - \\
\hline 1982 & 887 & $43 \%$ & - & - \\
\hline 1983 & $1482^{*}$ & $53 \%$ & - & - \\
\hline 1984 & $1445^{*}$ & $46 \%$ & - & - \\
\hline 1985 & $1375^{*}$ & $46 \%$ & - & - \\
\hline 1986 & 1488 & $42 \%$ & - & - \\
\hline 1987 & 1782 & $45 \%$ & - & - \\
\hline 1988 & 1923 & $44 \%$ & - & - \\
\hline 1989 & 1786 & $49 \%$ & - & - \\
\hline 1990 & 1929 & $49 \%$ & - & - \\
\hline 6th FYP & 5780 & $46 \%$ & 10.17 & 568 \\
\hline 7th FYP & 8908 & $46 \%$ & 14.87 & 599 \\
\hline total & 14,689 & $46 \%$ & 25.04 & 587 \\
\hline
\end{tabular}

N.B. Investment data include self-raised investments (non-central government funds). 1980 yuan calculated using national income deflators for the industrial sector (China Energy Databook). These data are based on statistical reports from energy conservation offices in local planning and economic commissions and may include some local funds allocated as general (non-conservation) loans and direct government expenditures.

* Only the sum of investment for the period 1983-1985 was available. The total was divided equally among the three years for the purpose of deflation.

Source: Liu Zhiping, ERI, 1993; SSB, 1991; China Project estimates, EAP, LBL, 1992 
Table 10. Unit Investment, Capital Construction Projects

A. Sixth FYP (1981-1985)

\begin{tabular}{|c|c|c|c|c|c|c|}
\hline Project & $\begin{array}{c}\text { Total } \\
\text { Investment [a] } \\
\text { (million yuan) }\end{array}$ & $\begin{array}{c}\text { Planned } \\
\text { Energy Saving } \\
\text { Capacity } \\
\text { (million tce/ } \\
\text { year) }\end{array}$ & $\begin{array}{c}\text { Completed } \\
\text { Energy Savings } \\
\text { Capacity [b] } \\
\text { (million tce/ } \\
\text { year) }\end{array}$ & $\begin{array}{c}\text { Gross } \\
\text { Unit } \\
\text { Investment } \\
\text { [planned] } \\
\text { (yuan/ } \\
\text { (tce/yr)) }\end{array}$ & $\begin{array}{c}\text { Gross } \\
\text { Unit } \\
\text { Investment } \\
\text { [completed] } \\
\text { (yuan/ } \\
\text { (tce/yr)) }\end{array}$ & $\begin{array}{c}\text { Net } \\
\text { Unit } \\
\text { Investment } \\
\text { [completed] [d] } \\
\text { (yuan/ } \\
\text { (tce/yr)) }\end{array}$ \\
\hline Cogeneration & $2,380.8$ & 4.21 & 2.13 & 566 & 1,118 & 560 \\
\hline Small Power Plant Replacement & 587.0 & 0.93 & 0.66 & 631 & 889 & -310 \\
\hline Small-Scale Fertilizer Plants & 542.3 & 1.75 & 1.35 & 310 & 402 & -151 \\
\hline Small-Scale Cement Plants & 66.3 & 0.20 & 0.20 & 328 & 328 & $-3,731$ \\
\hline Fuel-Gas Recovery & 534.7 & 1.77 & 1.47 & 302 & 364 & -972 \\
\hline District Heating & 311.7 & 1.01 & 0.60 & 309 & 520 & 520 \\
\hline Honeycomb Briquette & 78.9 & 1.04 & 1.04 & 76 & 76 & -30 \\
\hline Continuous Casting \& Rolling & 377.9 & 0.32 & 0.32 & 1,181 & 1,181 & $-7,044$ \\
\hline Coal Cleaning \& Processing & 172.8 & 0.95 & 0.68 & 182 & 254 & - \\
\hline Iron \& Steel Scrap Processing & 190.3 & 1.29 & 1.29 & 148 & 148 & - \\
\hline Power Generation w / Waste Heat & 143.7 & 0.34 & 0.34 & 423 & 423 & - \\
\hline Other Projects & 539.4 & 0.09 & 0.09 & 6,130 & 6,130 & - \\
\hline Total & $5,925.7$ & 13.90 & 10.17 & 426 & 583 & - \\
\hline
\end{tabular}




\section{Table 10. Unit Investment, Capital Construction Projects (continued)}

\section{B. Seventh FYP (1986-1990)}

\begin{tabular}{|c|c|c|c|c|c|c|c|}
\hline Project & $\begin{array}{l}\text { Total } \\
\text { Investment } \\
\text { [a] (million } \\
\text { yuan) }\end{array}$ & $\begin{array}{c}\text { Planned } \\
\text { Energy Savings } \\
\text { Capacity } \\
\text { (million tce/ } \\
\text { year) }\end{array}$ & $\begin{array}{c}\text { Completed } \\
\text { Energy Savings } \\
\text { Capacity [b] } \\
\text { (million tce/ } \\
\text { year) } \\
\end{array}$ & $\begin{array}{c}\text { Gross Unit } \\
\text { Investment } \\
\text { [planned] } \\
\text { (yuan/ } \\
(\text { tce } / y r)) \\
\end{array}$ & $\begin{array}{c}\text { Gross Unit } \\
\text { Investment } \\
\text { [completed] } \\
\text { (yuan/ } \\
\text { (tce/yr)) }\end{array}$ & $\begin{array}{c}\text { Net Unit } \\
\text { Investment } \\
\text { [planned] } \\
\text { (yuan/ } \\
\text { (tce/yr)) }\end{array}$ & $\begin{array}{c}\text { Net Unit } \\
\text { Investment } \\
\text { [completed] } \\
\text { (yuan/ } \\
(\text { tce/yr)) }\end{array}$ \\
\hline Cogeneration & $7,167.7$ & 9.91 & 5.70 & 723 & 1,257 & $817[\mathrm{~d}]$ & - \\
\hline Small Power Plant Replacement & 86.0 & 0.27 & 0.27 & 319 & 319 & $-1,015$ & $-1,015$ \\
\hline Small-Scale Fertilizer Plants & 126.8 & 0.45 & 0.45 & 279 & 282 & -418 & -422 \\
\hline Small-Scale Cement Plants & 39.6 & 0.12 & 0.12 & 338 & 338 & $-2,082$ & 5,116 \\
\hline Fuel-Gas Recovery & $1,207.2$ & 3.22 & 2.10 & 375 & 575 & $-1,197$ & -985 \\
\hline District Heating & 747.3 & 1.66 & 1.29 & 450 & 579 & -692 & -429 \\
\hline Honeycomb Briquette & 216.5 & 1.26 & 1.26 & 172 & 172 & 63 & 63 \\
\hline Coal Processing & 346.4 & 2.11 & 2.06 & 165 & 168 & - & - \\
\hline Raw Materials Savings [c] & 327.6 & 0.36 & 0.11 & 910 & 2,978 & - & - \\
\hline Other Projects & $1,043.5$ & 1.60 & 1.60 & 651 & 651 & - & - \\
\hline Total & $11,308.6$ & 20.95 & 14.96 & 540 & 857 & - & - \\
\hline
\end{tabular}

[a] Investment figures are uncorrected totals of investments made during the FYP period in current yuan. Annual data, and therefore figures in constant yuan, are not available. Data on further investment required to finish the remaining planned energy savings capacity are unavailable.

[b] Energy savings capacity completed by the end of the FYP period.

[c] In addition to energy savings, these projects resulted in 71,000 (36,000 planned) tons/year of raw materials savings capacity (not specified).

[d] ERI estimates.

N.B. Coverage and reporting of these data differ from those in Table 1. 
Cogeneration Cogeneration utilizes steam exhausted from generator turbines to supply heat. These systems are more efficient than meeting electricity and heat loads with separate dedicated systems. Compared with generating electricity with the small condensing turbines that existed in large numbers until programs to replace them were undertaken in the 1980s (see below), the overall efficiency of cogeneration systems is more than double (80-90\% (Gan Liequan, 1989)) since there is no heat loss in condensers. Cogeneration efficiency also exceeds that of dedicated heat supply boilers, which operate at 50-60\% efficiency (Gan Liequan, 1989).

Cogeneration projects in China have followed a variety of patterns. Some central plants supply heat for large numbers of nearby factories, while most supply only a single enterprise. Those in the latter category were not large enough to take advantage of scale economies, but in most cases construction of larger plants was impractical. Some projects involve replacing a small boiler with a higher performance boiler that meets the same heat load but generates electricity as well. Medium capacity power plants have been retrofitted (steam extraction or turbine operation at lothe $w$ vacuum) to supply heat factories and residences. A few plants operate near coal mines and use tailings. Most cogeneration projects constructed in the last decade were under $24 \mathrm{MWe}$ (comparable figures for heat load are not available). Both back pressure turbinesand steam extraction turbines were installed.

Projects have been concentrated in the textiles, paper, sugar, salt, and chemicals industries. Textile plants, for instance, requires a large heat supply, and both heat and electricity loads are relatively stable on daily and seasonal bases. Under such conditions the energy efficiency of cogeneration systems can reach $80 \%$, much higher than the average efficiency of $40 \%$ for separate electricity and heat supply. Since a stable heat load is required in cogeneration, the back-pressure turbines have been found to be more attractive in terms of their conservation benefits. Plants that operated less than about 4,000 hours a year, however, were found not to perform well economically. The smallscale cogeneration plants that have multiplied most rapidly in recent years have also suffered from problems in design (typically poor characterization of heat load resulted in improper sizing of equipment) and operation, leading to poor economic performance. With proper sizing, small cogeneration sets (designed to supply a single industrial site) are probably the most economic potential for expansion of cogeneration capacity. Further cogeneration investments should target medium-scale cogeneration plants (about $50 \mathrm{MWe}$ ) that supply several industrial sites and heating or cooling to residences. Because of difficulties experienced in managing large cogeneration projects, and irrationalities in pricing of heat (which remains controlled), projects of $100 \mathrm{MWe}$ and above will probably be inappropriate for most areas.

Cogeneration has received high priority in state capital construction budgets since 1980. In the Seventh FYP 7.17 billion yuan was invested towards total cogeneration capacity of 6,150 MWe, of which 3,570 MWe was completed and put into service (SPC, 1992). The cogeneration capacity put into service represented conservation capacity of $5.7 \mathrm{Mtce} /$ year at a GUI of 1,260 yuan/(tce/yr)

For Chinese plants, supplying heat is considered to be the primary function. The energy required for electricity generation, then is considered to be the difference between actual energy consumption at the cogeneration plant and that required to provide the same heat supply from a dedicated heating boiler. Energy savings are then 
the difference between heat rates for a conventional power plant and that calculated using residual energy consumption at the cogeneration plant. Similarly, the investment in conservation (i.e., electricity generation capacity) is considered to be residual investment after subtracting that needed for equivalent heat supply capacity. Using this knd of comparison, ERI has estimated the NUI of cogeneration projects to have been 817 yuan/(tce/yr). ${ }^{1}$ A different source reported that unit investment in the electricity generation part of a set of cogeneration projects (residual after subtracting estimated heat supply capacity cost) was only 1,307 yuan $/ \mathrm{kw}$, compared with 1,800 yuan $/ \mathrm{kw}$ for domestically manufactured $200 \mathrm{MW}$ thermal generators, and NUI only 440 yuan/(tce/yr) (Wang Ruwu, 1991).

Increasing Generation Capacity in Small-Size Power Plants The total generating capacity of China's small and medium ${ }^{2}$ power plants is around $20 \mathrm{GW}$ and their typical rates of coal consumption are between 600 and $700 \mathrm{gce} / \mathrm{kWh}$. Given that heat transfer rates increase significantly with increases in heat exchanger size and that higher heat transfer increases thermal efficiency, the coal currently burned in China's small and medium power plants could supply up to $15 \mathrm{GW}$ of additional capacity if used in larger plants.

In 1981 the Chinese began replacing small generators with larger ones and converting some small generators to cogeneration systems ${ }^{3}$. All told, $270 \mathrm{MW}$ of original capacity in small plants was replaced by $450 \mathrm{MW}$ of capacity in large plants by the end of the Seventh FYP for a net increment capacity of $180 \mathrm{MW}$. The rate of coal consumption for the newly resized plants was about $430 \mathrm{gce} / \mathrm{kWh}$, representing an increase in thermal efficiency of roughly $30 \%$.

Investments in these projects totaled 86 million yuan, and the energy conservation capacity from the program totaled $0.27 \mathrm{Mtce} / \mathrm{yr}$ for an overall GUI of 319 yuan/(tce/yr). However, accounting for the equivalent cost of the additional generation capacity 4 realized from the projects gives a substantial negative NUI of about $-1,080$ yuan/(tce/yr). As with the cogeneration projects above, these aggregate figures may disguise great variation between projects.

Renovation of Small-scale Fertilizer Plants Small chemical fertilizer plants 5 play a major role in China's fertilizer production capacity accounting for approximately $60 \%$ of the national output. Pursuant to this, the Chinese central government has provided direct funding and low-interest loans for energy conservation projects in small fertilizer plants.

1 The alternative mode of electricity generation was assumed to be a $6 \mathrm{MW}$ power plant, a size that self-generators or municipalities might build to meet incremental demand.

2 Chinese energy experts commonly define large power plants as those $100 \mathrm{MW}$ installed capacity and above, medium plants as those $6 \mathrm{~kW}$ to $100 \mathrm{MW}$, and small plants as those under $6 \mathrm{~kW}$.

3 These projects are separate from those categorized as "cogeneration" projects above.

$4 \mathrm{We}$ use an average of 2,000 yuan/ $\mathrm{kW}$ for new electricity supply capacity, including power plant capacity and transmission, in the Seventh FYP. Wirtshafter and Shih, 1990 reported that power plant capacity costs (exclusive of transmission) for Henan Province in 1986 were 1,250 yuan/kW for $200 \mathrm{MW}$ units and 1,540 to 1,680 yuan $/ \mathrm{kW}$ for $12 \mathrm{MW}$ units.

5 For synthetic ammonia (the major component of nitrogenous fertilizer and the most energy intensive step in the manufacturing process) small plants are those that produce less than $25 \mathrm{kt} / \mathrm{yr}$. Medium plants typically produce $40-80 \mathrm{kt} / \mathrm{yr}$, and both small and medium plants use coal as feedstock. Large plants manufacture on the order of $300 \mathrm{kt} / \mathrm{yr}$ and use natural gas, naphtha, or heavy oil as feedstock (Wang Qingyi, 1993). 
With Seventh FYP investments totaling nearly 127 million yuan, the energy conservation projects applied to small fertilizer plants were: recovery and utilization of waste gases (e.g., blow-by gas, emitted gas, and regenerated gas), heat recovery from cooling and heat-exchange systems, and renovation of equipment in synthesis towers.

The results were two-fold. The energy intensity of fertilizer production dropped from $2358 \mathrm{kgce} / \mathrm{t}$ in 1985 to $2254 \mathrm{kgce} / \mathrm{t}$ by 1990, representing an annual rate of decrease of $4.4 \%$ per year and a total of $0.454 \mathrm{Mtce} / \mathrm{yr}$ of conservation capacity 1 . This gives a GUI of 279 yuan/(tce/yr). The other important result was a $382 \mathrm{kt}$ increase in fertilizer production capacity. Accounting for the cost of an equivalent increase in production capacity through construction of new medium-scale fertilizer plants, ${ }^{2} \mathrm{NUI}$ is -418 yuan/(tce/yr), indicating strong non-energy benefits.

Renovation of Small-size Cement Plants The renovation of small ${ }^{3}$ cement plants was a key program in China's energy conservation effort. In the Sixth FYP 40 cement kilns were remodeled, resulting in both production capacity expansion of $2.05 \mathrm{Mt}$-cement/yr and energy conservation capacity of $202 \mathrm{ktce} / \mathrm{yr}$. Seventh FYP investments were smaller and led to production capacity increases totaling $708 \mathrm{kt}$ and a further energy conservation capacity of $117 \mathrm{ktce} / \mathrm{yr} .{ }^{4}$ In general, investments in the renovation of small cement plants have resulted in plant energy intensity declines of about $20 \%$ and production increases of about $30 \%$.

GUI for these projects was 338 yuan/(tce/yr) with an NUI of $-2,080$ yuan/(tce/yr) based on a cost of 400 yuan per annual ton for new cement production capacity. The substantial investment benefit reflects the difference in cost between renovating existing plants to incorporate rotary kilns and building new, medium-scale plants with rotary kilns, not between the former and new production capacity using conventional vertical kilns.

Recovery of Fuel-Gas Emissions Fuel-gas recovery from industrial production processes (such as coke oven and blast furnace emissions in steel production and coalbed methane in coal production) provided multiple benefits, namely conserving energy, supplying urban households with fuel-gas, and reducing urban air pollution associated with emissions of fuel-gases.

Total investment in fuel-gas recovery was over 1.2 billion yuan resulting in fuelgas recovery capacity of almost 6 million $\mathrm{m}^{3} /$ day and energy conservation capacity of $2.1 \mathrm{Mtce} / \mathrm{yr}$, at a GUI of $375 \mathrm{yuan} /(\mathrm{tce} / \mathrm{yr}) .{ }^{5}$ In some cases large portions of project funds went to the purchase and installation of the pipeline systems needed for

\footnotetext{
1 In the Sixth FYP intensity decreased 22\%. Two possible explanations for the sharp decline in rate of conservation are the drop in investment in this category of project (from 542 to 127 million current yuan in the Sixth and Seventh FYPs respectively), and the lack of opportunities for further savings of the same magnitude in the same project category. The Chinese expect the conservation rate to rise again to the level of the Sixth FYP in the Eighth FYP (1991-1995) with the implementation of planned process renovations to reduce coal's role in fertilizer production from fuel and feedstock to feedstock only.

2829 yuan per annual ton of fertilizer production capacity.

3 Small cement plants use vertical kilns and generally have annual capacities under $50 \mathrm{kt}$. Medium and large plants have capacities up to and over $1 \mathrm{Mt} / \mathrm{yr}$ respectively, and use rotary kilns.

4 Funding in the Sixth FYP was significantly higher than in the Seventh FYP (66.3 and 39.6 million current yuan respectively), but GUIs were similar (328 and 338 current yuan/(tce/yr)).

5 GUI based on "completed" investment was substantially higher at 575 yuan/(tce/yr).
} 
distribution, whereas in other cases money was only spent on recovery, with gas being fed into an existing distribution network. It is therefore difficult to interpret the GUI figure and to compare these projects to analogous fuel-gas supplies in order to calculate NUI. Comparing these projects to investments in coal gas generation and distribution networks ( 55 yuan per thousand $\mathrm{m}^{3}$ of delivered gas per year) overstates the relative attractiveness of fuel-gas recovery, but the very low NUI of $-1,200$ yuan/(tce/yr) suggests that in general the projects were sensible form the point of view of saving energy.

District Heating Systems Space heating of buildings in the northern half of China is allowed for five to six months of every year. State statistics indicate that at the beginning of $1981,93 \%$ of national space heating demand was met by small decentralized boilers (less than $10 \mathrm{t}$-steam $/ \mathrm{hr}$ ) and household stoves. Starting in the Sixth FYP, district heating systems were installed and combined with new cogeneration plants or new, larger boiler systems in order to replace small boilers and stoves. Like fuel-gas recovery, these projects reduced urban indoor and outdoor air pollution and increased the efficiency of heat generation. Three types of district heating systems were installed:

- industrial (particularly iron and steel production) waste heat utilization for neighboring residences;

- district boiler systems to replace decentralized small boilers serving high population density urban areas (increasing the conversion efficiency, but not necessarily the distribution efficiency, since longer pipes will be needed);

- addition of seasonal cogeneration capability to existing, electricity-only power plants that were not primary suppliers to the local grid.

Compared to average energy consumption of decentralized heating systems ( 28 $\mathrm{kgce} /$ square meter), average energy consumption of district heating systems is $25 \%$ lower (21 kgce/square meter; Chen Heping, 1989). Total investment in these projects during the Seventh FYP was 747 million yuan, resulting in space heating capacity of 32.51 million square meters and an energy conservation capacity of $1.29 \mathrm{Mtce} / \mathrm{yr}$. The GUI from district heating projects was 578 yuan/(tce/yr). Based on an estimated average cost of heat supply from conventional decentralized sources of 40 yuan $/ \mathrm{m}^{2}$ (compared to 23 yuan $/ \mathrm{m}^{2}$ for the conservation projects), we obtain an NUI of -692 yuan $/($ tce $/ y r)$.

Honeycomb Briquettes Coal accounts for $75 \%$ of the total commercial energy consumed by households in China; coal gas, natural gas, and LPG were available to only $11 \%$ of the population, or almost half of the urban population, in $1991 .^{1}$ Of households in urban areas and rural towns where coal is available, four-fifths use coal for cooking, with serious consequences for indoor and outdoor air quality. Forming coal into briquettes can greatly improve combustion characteristics and is an effective

1 Based on statistics from Editorial Committee of the China Environmental Yearbook, 1992 and SSB, 1993. 
way to conserve energy and control urban air pollution. "Honeycomb" briquettes 1 used in cooking stoves have much higher conversion efficiencies (up to $45 \%$ ) than raw coal (about $15 \%$ ), reducing coal use significantly. In the Sichuan Province, average daily coal use per household was found to be 2 tons if raw coal was used, 1.5 tons if coal shaped by hand into balls was used, and only one ton if honeycomb briquettes were used (Jiang Zhenping, 1989). The Chinese have pursued mass production of these briquettes, along with dissemination of the stoves required to use them, as an energy conservation and environmental protection measure. They are credited with stabilizing or reducing ambient levels of air pollution in many urban areas.

Total investment in honeycomb briquette production during the Seventh FYP was 217 million yuan, resulting in a production capacity of 6.86 million $\mathrm{t} / \mathrm{yr}$. The energy conservation capacity resulting from the shift from raw coal to honeycomb briquettes was $1.26 \mathrm{Mtce} / \mathrm{yr}$ at a GUI of 172 yuan/(tce/yr). The NUI for these projects was 63 yuan/(tce/yr) when compared to and alternative of making briquettes or coal balls in the home by hand, at an estimated equivalent labor cost of 20 yuan $/ t$.

\section{Technical Updating and Transformation Investments}

Energy conservation capacity resulting from slightly over one-third of the in technical updating conservation investments in the Seventh FYP was $9.59 \mathrm{Mtce} / \mathrm{yr}$ (see Table 11). ${ }^{2}$ Waste heat utilization, power generation from waste pressure, renovation of industrial boilers and furnaces, and production of high-efficiency end-use equipment accounted for three-quarters of the conservation capacity in this category of investments. Unless otherwise noted, the following discussion of technical updating investments refers only to investments in the first three years of the Seventh FYP (19861988; completed conservation capacity: $5.9 \mathrm{Mtce} / \mathrm{yr}$; see Table 12).

\footnotetext{
1 "Honeycomb" briquettes are cylindrical with round holes running between the two faces. They generally weigh $750 \mathrm{~g}$ to $1 \mathrm{~kg}$ and often incorporate a lime binder to reduce $\mathrm{SO}_{2}$ emissions.

2 If the remainder of investments resulted in savings at the same unit cost (i.e., 394 yuan/(tce/yr)) then total energy savings capacity from all technical updating investments would have been almost 27 Mtce/year.
} 
Table 11. Technical Updating Investment in Energy Conservation, 1981-1990

\begin{tabular}{|c|c|c|c|c|c|}
\hline Year & $\begin{array}{l}\text { Total Technical } \\
\text { Updating Investment } \\
\text { (million1980 yuan) }\end{array}$ & $\begin{array}{l}\text { Fraction of Total } \\
\text { Conservation } \\
\text { Investment }\end{array}$ & $\begin{array}{l}\text { Partialt } \\
\text { Technical Updating } \\
\text { Investment } \\
\text { (million } 1980 \text { yuan) }\end{array}$ & $\begin{array}{l}\text { Total } \\
\text { Energy Savings } \\
\text { Capacity } \\
\text { (Mtce/year) }\end{array}$ & $\begin{array}{l}\text { Unit Cost of } \\
\text { Energy Savings } \\
\text { (1980 yuan/ } \\
\text { (tce/yr)) }\end{array}$ \\
\hline 1981 & 895 & $60 \%$ & 894 & 3.85 & 233 \\
\hline 1982 & 1196 & $57 \%$ & 956 & 4.55 & 210 \\
\hline 1983 & 1327 & $47 \%$ & 1021 & 4.30 & 237 \\
\hline 1984 & 1693 & $54 \%$ & 1167 & 4.46 & 262 \\
\hline 1985 & 1612 & $54 \%$ & 1142 & 4.05 & 282 \\
\hline 1986 & 2049 & $58 \%$ & 913 & 2.47 & 370 \\
\hline 1987 & 2211 & $55 \%$ & 1029 & 2.61 & 395 \\
\hline 1988 & 2409 & $56 \%$ & 895 & 2.25 & 398 \\
\hline 1989 & 1832 & $51 \%$ & 516 & 1.27 & 408 \\
\hline 1990 & 1972 & $51 \%$ & 423 & 1.00 & 423 \\
\hline 6th FYP & 6724 & $54 \%$ & 5180 & 21.20 & 244 \\
\hline 7th FYP & 10,473 & $54 \%$ & 3777 & 9.59 & 394 \\
\hline total & 17,197 & $54 \%$ & 8957 & 30.79 & 291 \\
\hline
\end{tabular}

+ Figures within the box are only for that portion of technical updating investment for which data on resulting energy savings capacity are available.

N.B. Investment data include self-raised investments (non-central government funds). 1980 yuan calculated using national income deflators for the industrial sector (China Energy Databook). These data are based on statistical reports from energy conservation offices in local planning and economic commissions, and may include some local funds allocated as general (non-conservation) loans and direct government expenditures.

Coverage and reporting of these data differ from those in Table 1.

Source: Liu Zhiping, ERI, 1993; SSB, 1991; China Project estimates, EAP, LBL, 1992 
Table 12. Unit Investment, Technical Updating Projects

A. Sixth FYP (1981-1985)

\begin{tabular}{lccc} 
Project & $\begin{array}{c}\text { Total } \\
\text { Investment } \\
\text { (million yuan) }\end{array}$ & $\begin{array}{c}\text { Energy Savings } \\
\text { Capacity } \\
\text { (million tce/year) }\end{array}$ & $\begin{array}{c}\text { GrossUnit } \\
\text { Investment } \\
\text { (yuan/(tce/yr)) }\end{array}$ \\
\hline
\end{tabular}

Waste Heat \& Pressure Recovery

Boiler \& Heating System Retrofits

Industrial Furnace \& Kiln Retrofits

\begin{tabular}{rrr}
$1,574.9$ & 4.43 & 356 \\
963.0 & 3.50 & 275 \\
808.0 & 2.66 & 304 \\
622.0 & 1.85 & 337 \\
136.4 & 0.64 & 212 \\
170.7 & 0.74 & 230 \\
61.7 & 0.47 & 132 \\
106.1 & 1.13 & 94 \\
$4,442.8$ & 15.41 & 288 \\
\hline
\end{tabular}

B. First three years of Seventh FYP (1986-1988)

Industrial Equipment Renovation (various)

High-Efficiency Equipment Design \& Mfg

Mixing Coal to Utility Boiler Specifications

Coal Mine Tailing Utilization

Total

Total

Investment
Energy Savings
Capacity

GrossUnit

Investment

(million tce/year)

(yuan $/($ tce $/$ yr))

Net Unit

Investment

Project

(million yuan)

1.50
1.00
1.20
0.90
0.19
0.96
0.08
0.08

$2,842.2$

5.90

542
325
559
737
690
215
131
324

482
yuan/(tce/yr))

Waste Heat \& Pressure Recovery

Boiler \& Heating System Retrofits

813.3

324.7

670.6

661.5

131.7

Industrial Equipment Renovation (various) [b]

High-Efficiency Equipment Design \& Mfg

Mixing Coal to Utility Boiler Specifications [b]

24.6

42

325

559

737

690

215

Coal Mine Tailing Utilization

[a] Figures represent costs of savings from electricity generation and heat supply investments respectively. Reported in Rational Resource Utilization Handbook, p. 819

b] No discussion in text.

N.B. Coverage and reporting of these data differ from those in Table 1. 
Utilization of waste heat and pressure for power and heat Projects to convert waste heat and pressure into useful heat and electricity were considered very successful in the Sixth FYP, yielding increased power generation capacity and increased thermal efficiencies at a moderate GUI of 423 yuan/(tce/yr). As a result, funding for such projects increased from 143 million yuan in the Sixth FYP to 810 million yuan in just the first three years of the Seventh FYP. Additions to installed power generation capacity resulting from waste heat and pressure utilization totaled $512 \mathrm{MW}$ (we estimate that total installed capacity from these projects through 1990 was $926 \mathrm{MW}$ ). Energy conservation capacity totaled $1.5 \mathrm{Mtce} / \mathrm{yr}$ at a GUI of 542 yuan/(tce/yr). NUIs for heating and power generation with waste heat and pressure are reportedly 48 and -34 yuan/(tce/yr), respectively (SPC, 1992).

In the Seventh FYP, 502 waste heat and pressure utilization projects were selected mainly in industries with high-energy intensities such as iron and steel, chemicals, aluminum, and paper. High-temperature waste heat from chemicalmanufacturing processes (synthesis of carbon black, sulfuric acid, formaldehyde, and aniline) was recovered and used to raise steam and generate power. Similar strategies, using the waste heat in blast furnaces and stack-gases to generate power, were followed in the metallurgical industry. The paper, sugar, and aluminum industries used waste pressure to generate power and supply on-site, low-quality steam using back-pressure turbines. Steel works generated power by utilizing pressure differentials between different locations in blast furnaces (luding yacha). Waste heat from stack-gases was also used to preheat air fed into blast furnaces, improving thermal efficiency an average of 4$6 \%$ (Zhao Yuying, 1988). In the building materials industry waste heat from blast furnaces is used to dry primary ceramic and brick products.

Renovation of industrial boilers and heat supply systems China has 400,000 coal-fed boilers that can supply $800 \mathrm{kt}$-steam/hr for industrial processes and space-heating applications. Before 1981, these boilers had an average conversion efficiency of $60 \%$, far below the average conversion efficiency in developed countries of $85 \%$ (for heat and steam applications). One third of total national coal consumption (over $300 \mathrm{Mtce} / \mathrm{yr}$ ) was devoted solely to boilers. Improvements in the performance of boilers and heat supply systems thus held high priority in Chinese energy conservation planning during the Seventh FYP.

The main strategies used to improve performance were the elimination of small and inefficient boilers, the improvement of conversion efficiencies in medium and large boilers, and the reduction of losses in heat distribution systems. Employing technical renovations such as matching fuel characteristics to boiler requirements, installating and using advanced combustion equipment (including automated combustion controls), and renovating associated equipment, conversion efficiencies in medium and large boilers increased an average of $10 \%$. Reducing heat losses in heat distribution systems involved insulating pipes and valves and outright replacing some sections of pipeline.

Investments totaling 325 million yuan were made in 652 projects between 1986 and 1988, yielding a total energy conservation capacity of $0.998 \mathrm{Mtce} / \mathrm{yr}$ at a GUI of 325 yuan/(tce/yr). Although significant improvements have been made in this area, great 
potential for energy conservation still remains through improving equipment design, the degree of automation, operator skills, and managerial systems.

Renovation of industrial furnaces and kilns Only a handful of China's 114,000 industrial furnaces and kilns used advanced technologies (Zhou Fengqi, 1989). Kilns in the metallurgical, chemical, and building materials industries account for $90 \%$ of energy consumed in industrial furnaces and kilns nationwide. Most renovations to kilns were made during scheduled periods of major repairs. The reported cost of renovation projects includes the expense of bonding kiln interiors, and normal repairs accounted for as much as $60 \%$ of total investments (Liu and Qin, 1989).

Investments totaling 670 million yuan were made in 683 projects. Table 13 presents the types of furnaces and kilns targeted for renovations during the Seventh FYP. In general, technical updating projects were aimed at both reducing energy intensity and improving product quality. Typical renovations were remodeling furnace structures, installing insulation to reduce heat loss, installing high-efficiency heat recovery equipment to improve thermal efficiency, introducing advanced combustion technologies (e.g., plane flame burning jet, self pre-heating burning jet, high-speed burning jet), and installing advanced instrumentation and computer process controls.

The total energy conservation capacity from this program was $1.2 \mathrm{Mtce} / \mathrm{yr}$ at a GUI of 558 yuan/(tce/yr) and an NUI of 223 yuan/(tce/yr). This NUI figure was established by ignoring the $60 \%$ of investment funds used for basic repairs and not direct energy conservation measures (Liu and Qin, 1989).

Efforts to improve industrial furnace and kiln performance were fairly successful with $62 \%$ of heating furnaces achieving performance standards established by the Ministry of Metallurgy. China's most energy-efficient furnaces are now at the level of performance of industrial furnaces in developed countries.

Renovation of various industrial processes Nearly 400 separate industrial process lines were renovated during the Seventh FYP. The types of energy conservation measures implemented varied greatly, thus making it difficult to generalize the character or success of the program. We can, however, describe some process renovations as examples of the range of projects undertaken. Note that the units of measurement are industry- or process-specific, limiting quantitative comparisons between projects.

In the iron and steel industry, the most significant process renovation was the substitution of coal powder for coke in blast furnaces, with $80 \%$ of state-run and $50 \%$ of the local government-run enterprises adopting the practice. By 1988, 2 million tons of coal powder had been substituted for 1.6 million tons of coke annually (Wu and Meng, 1991). Other process renovations were structural changes to furnaces and replacing two-jet with three-jet configurations in the hydrogen-rejection portion of open hearth furnaces. Renovations in iron-and steel-making reduced the average oil consumption by $7 \mathrm{~kg}$ per ton of steel and extended furnace life. ${ }^{0}$ The renovation of long-distance pipeline systems and use of high-efficiency furnaces to reduce oil viscosity during

0 This and the following three examples are from Zhao Yuying, 1988. 


\section{Table 13. Furnace and Kiln Types Renovated in the Seventh FYP by Industry}

\begin{tabular}{ll} 
Industry & Furnace or Kiln Type \\
\hline Iron and Steel & heating furnaces \\
Building Materials & $\begin{array}{l}\text { cement kilns } \\
\text { ceramic kilns } \\
\text { plate glass kilns }\end{array}$ \\
Chemical & $\begin{array}{l}\text { heating furnaces } \\
\text { soda ash calcining furnaces } \\
\text { normal pressure heating furnaces } \\
\text { (changiianya jiarelu) }\end{array}$ \\
Non-ferrous Metals & $\begin{array}{l}\text { electrical furnaces } \\
\text { melting furnaces } \\
\text { wire heating furnaces }\end{array}$ \\
Light Industry & $\begin{array}{l}\text { furnaces for household glass, enamel, } \\
\text { and ceramics }\end{array}$ \\
Machine Building & $\begin{array}{l}\text { casting furnaces } \\
\text { forge heating furnaces } \\
\text { heat treating furnaces }\end{array}$ \\
\hline
\end{tabular}

Source: ERI

transport together increased the energy-efficiency of oil pipeline transport by $15-20 \%$. Changes in the multiple stage evaporation processes in various industries (e.g., the change from a two-stage to a three-stage process in caustic soda production) produced significant increases in efficiency. Improvements in fermentation processes increased the energy-efficiency of wine-making by $40 \%$.

Aggregate investment in various industrial process renovations totaled 660 million yuan and yielded energy conservation capacity of $0.897 \mathrm{Mtce} / \mathrm{yr}$. Average GUI was 738 yuan/(tce/yr), twice the program's GUI in the Sixth FYP. This higher GUI was brought about by the increasing degree of difficulty of technical renovations and reflected the far-reaching nature of process changes.

Manufacture of high-efficiency equipment Conventional electromechanical equipment such as industrial motors, fans, and pumps consume approximately $30 \%$ of all electricity produced in China. Improving the energy efficiency of such equipment has the potential to reduce their electricity consumption by $20 \%{ }^{1}$

In 1986, the Chinese central government issued provisions for the mandatory retirement of obsolete energy-intensive equipment. This action came in conjunction

1 ERI estimate. 
with investments in the design and manufacture of high-efficiency equipment. With investments totaling 205 million yuan, over 1400 types of high-efficiency electromechanical equipment were manufactured and distributed in the first three years of the Seventh FYP. The use of new equipment provided energy conservation capacity of $0.959 \mathrm{Mtce} / \mathrm{yr}$ at a GUI of 215 yuan/(tce/yr).

Utilization of coal mine tailings As part of China's rational utilization of coal resources planning effort, the integrated utilization of coal mine tailings (CMT), substituting for coal as both fuel in power generation and raw material in cement and brick production, was considered a significant energy conservation measure during both the Sixth and Seventh FYP. ${ }^{2}$

Mine mouth cogeneration with CMT, in particular, was developed in parallel with the development of fluidized-bed combustion technology after 1980.3 By the end of 1990, total installed generating capacity of CMT power stations was $215 \mathrm{MW}$, producing $914 \mathrm{TWh} / \mathrm{yr}$ of electricity, 23.57 million yuan/yr in generator-revenues, and an energy conservation capacity of $0.3 \mathrm{Mtce} / \mathrm{yr}$. By 1988 almost $1.9 \mathrm{Mt} / \mathrm{yr}$ of CMT (1.5\% of annual CMT production) was being used to generate power.

Fifty cement plants (with a combined production capacity over 2 million tons/yr) substituted CMT for a portion of clay as raw material. In the production of bricks, those that incorporated CMT in addition to the usual clay proved to possess higher strength and corrosion resistance than conventional clay bricks and passed the state standards for sintered bricks. Brick production with CMT reduced energy intensity by $15-30 \%$, avoided land degradation associated with clay extraction, and contributed to solving the problem of CMT disposal. According to state statistical data on building materials, approximately 40 billion CMT bricks were produced annually in China by the end of 1990.4

During the Sixth FYP, investments in the integrated utilization of CMT totaled 106 million yuan resulting in the use of 6.6 million tons of CMT and an energy conservation capacity of $1.13 \mathrm{Mtce} / \mathrm{yr}$. Between 1986 and 1988, investments totaled 24.6 million yuan and resulted in the use of 0.5 million tons of CMT. The energy conservation capacity thus obtained was $0.076 \mathrm{Mtce} / \mathrm{yr}^{5}$ with a GUI averaging 323 yuan/(tce/yr).

\footnotetext{
2 Partly as a result of these investments, by 1989 about $20 \%$ of CMT generated, or nearly $25 \mathrm{Mt}$, was being used each year for various purposes. Related programs were aimed at using other waste products and scraps from industrial processes. One source claims that by the end of the Seventh FYP, 25\% of ash from power plants was used in brick production (Zhu Liandong, 1991).

3 The development of fluidized-bed combustion technology was a key aspect of the National Key Development Plan for Science and Technology, ca. 1980.

4 ERI estimates.

5 Investments in CMT cogeneration were not included in the aggregate CMT figures for the period 1986-1988.
} 


\section{Problems Encountered in the Seventh Five-Year Plan Investment Programs}

Energy conservation work in the Seventh Five Year Plan was not carried out without problems. A 1988 survey of the status of energy management and energy savings for large and medium industrial enterprises indicated six important problems ( $\mathrm{He}$ Xuesheng, 1991):

(1) Lack of specific energy savings policies and regulations. Most enterprises complained that the "Regulations Regarding Energy Conservation Management" were too vague and wanted them to be revised and expanded.

(2) Lack of incentives for energy savings. Fifty-eight percent of the respondents had energy costs less than $15 \%$ of their total operational expenses, and $27 \%$ had energy costs under $5 \%$ of their total operational expenses.

(3) Lack of attention from top officers of enterprises. For many firms, energy conservation was only important on paper, not in practice. In these cases, managers' attitudes have become major obstacles in energy conservation work.

(4) Lack of energy conservation funding. Forty-eight percent of surveyed enterprises had raised energy conservation funds by themselves, $45 \%$ relied on loans and self-raised money, and $8 \%$ relied on loans entirely. Most firms indicated that additional funds were required for energy conservation investments.

(5) Lack of training for energy management staff and equipment operators. Forty-eight percent of surveyed enterprises acknowledged that high energy consumption was caused by a lack of technical and professional ability on the part of equipment operators.

(6) Energy shortages have impeded energy savings. Intermittent blackouts and variation in the quality of coal caused increases in energy consumption per unit product.

Energy conservation was not integrated into broader enterprise reforms of the 1980s. In particular, there was no link between energy conservation and the enterprise contract-responsibility system. Under this system, introduced at the beginning of 1988 for most enterprises, managers of state enterprises were to sign contracts with the supervising authority guaranteeing that the enterprise would meet certain performance targets, e.g., GOV, physical output, profit, and tax remittances. Few of these contracts specify energy conservation goals. Managers' interests in profits and levels of output were strengthened at the expense of other goals. In some cases planning authorities reduced energy allocations to enterprises that had made significant energy savings because of the practice of basing allocations on use in the previous year. At the same time they did not reduce allocations to punish enterprises with bad records of energy savings, discouraging energy conservation at enterprises (this phenomenon is referred to as "whipping the fast ox").

Following are some of the challenges that must be addressed above the enterprise level in the continuing program of energy conservation investments. 


\section{Inadequate capital investment}

A severe shortage of investment capital during the Seventh FYP-stemming largely from the shifting of tax revenues and funds allocation from the central to local governments-hobbled centrally sponsored energy conservation activities. Investment in energy conservation projects in the Seventh FYP was about 3.2 billion yuan annually, only $1.3 \%$ of investment nationwide. In contrast, the corresponding energy conservation investment ratios in France, the U.S., and Japan were $3.5 \%, 2 \%$, and $2 \%$, respectively (Ye Qing, 1989). In real terms, energy conservation investment in the Seventh FYP increased only $16 \%$ over the Sixth FYP, with technical updating investment actually decreasing $27 \%$. Furthermore, loans for energy conservation declined as a percentage of total loans for technical updating investment. Enterprises invested most internally raised funds in improving productivity and profitability rather than energy efficiency. Many projects with significant energy benefits were not financed; consequently conservation fell far short of potential. Throughout the entire period GUI remained far below the cost of new energy supply, indicating the existence of significant conservation potential that might have been tapped had more capital been available.

\section{Distortion of energy prices}

Little progress was made in liberalizing energy prices in the 1980s. Energy price distortions made cost-benefit comparisons much less useful in ranking investments. China's two-tier price system (which persists in weaker form as of this writing) encompasses plan prices fixed by the central government and freely floating market prices. State-owned enterprises received allocations of energy at low plan prices, supplementing allocations with purchases at market prices. Collective and other enterprises obtained all energy inputs from markets or barter. In the Seventh FYP most state-owned enterprises still obtained most of their energy inputs through allocations, and energy accounted for a very small portion of their cost structure. Even in energyintensive industries in which energy costs represent a large part of the total, the inducements to maximize output tended to be much stronger than those to minimize costs. There was consequently little motivation to invest in energy conservation. In 19901080 yuan of GNP was produced for each tce of energy consumed (SSB, 1992), while enterprises saved roughly 250 to 300 yuan for every tce conserved. 6 Under such circumstances, continued and active government involvement is crucial to conservation efforts.

\section{Weak restrictions on energy-intensive equipment}

In spite of the adoption of regulations requiring that certain categories of extremely energy-intensive equipment be retired from service, no mechanisms for executing the regulations and monitoring compliance were established. The details of implementation were left to local authorities, who were free to interpret the policy statements as strictly or as loosely as was convenient. Although many policy statements

\footnotetext{
6 ERI estimates.
} 
were aimed specifically at suppressing or entirely banning small coal-fired condensing power plants, diesel-fired power plants, small coke ovens, and small blast furnaces, these facilities continued to be built rapidly. The pressure to expand output figured much more prominently in the calculations of the local authorities that approved and supported construction of these facilities than did considerations of the plants' cumulative impact on overall energy demand.

\section{Low energy efficiency in rural industry}

Township and village enterprises (TVEs) continue to grow in rural areas; by 1991 rural enterprises accounted for nearly $30 \%$ of industrial GOV, up from $10 \%$ a decade earlier (Whiting, 1993). Their impact of overall industrial energy intensity cannot be ignored. Although some TVEs possess technically advanced and highly efficient equipment, many more have obsolete and energy-intensive equipment, much of which was discarded from state-owned enterprises or made by the enterprises themselves without regard for government-issued energy standards. For instance, some small blast furnaces of 100 cubic meters volume are still in operation at local iron works. In 1990, 20 million tons of coke, 65\% more than in 1985, was produced in earthen "beehive" coke ovens, which are highly polluting and produce an inferior product at much higher energy intensity than modern coke ovens. The challenge of balancing rural economic development objectives and energy conservation goals should receive more attention from national and local policymakers.

\section{Inconsistent evaluation methods}

The evaluation methods for energy conservation investments are simple and easy to use (and are in fact very similar to the GUI and NUI formulas used in this paper), but very important factors, such as capital cost, discount rate, operating cost, project lifetime and input price changes, are omitted. Comparisons between energy conservation and energy supply projects based on these methods may be misleading and encourage investments that are not optimal from a social or national perspective. For example, based on the evaluation methods employed above, renovating existing equipment appeared to be much more attractive than designing and manufacturing new and efficient equipment. Continued use of such methods may hinder development of advanced technology, new processes, and equipment and may slow the taking advantage of economies of scale to conserve energy in the long term. New and easily taught methods for energy investment evaluation, based on life-cycle cost principles, need to be developed.

\section{Lack of managerial and other incentives}

Energy management requirements in management responsibility contracts, under which enterprise managers assume responsibility for fulfilling contract targets such as output, profits, and tax remittances, have been weak or entirely lacking. A survey found that managers generally have incentives to maximize output as quickly as possible during the several years they occupy their position and derive no benefit from increasing long-term enterprise energy efficiency (He Xuesheng, 1991). On the subject 
of monetary incentives within enterprises, the same survey revealed that nearly onefourth of enterprises either rewarded the meeting of efficiency standards without fines for excessive energy consumption, or distributed funds intended to reward conservation evenly without regard to actual performance. ${ }^{7}$ Although three-quarters of survey respondants indicated that both fines and awards were applied based on energy performance, anecdotal evidence suggest that this percentage may be too high. In general only state-owned enterprises (which currently account for half of China's industrial output) have implemented systems of rewards and penalties based on energy performance. Also, degree of implementation at enterprises changes over time; many enterprises set awards based on performance of the plant or workshop rather than the individual worker, and many enterprises cease implementation of such systems after a time. In general, the awards or penalties based on energy performance are small compared to those based on achievement of output targets, both for managers and for workers.

7 Separate figures for the two categories were not available. 


\section{References $^{+}$}

Anonymous, An energy conservation technology demonstration project, Zhongguo Jiancai (China's Building Materials), No. 7, 1989.

Chen Heping, "Building energy conservation potential and policy in China," Zhongguo Nengyuan (China Energy), No. 2, 1989.

Chen Min, Energy conservation through technology improvement in the building materials industry, 1991 Nian Quanguo Jieneng Xuanchuanzhou Jieneng Baogao Wenji (Collected Energy Conservation Papers from the 1991 National Energy Conservation Propaganda Week), Beijing: Nengyuan Chubanshe, October, 1991.

Dai Yande, Zhou Fengqi, Zhou Dadi, Wang Bangcheng, Wang Shumao, Liu Zhiping, HU Xiaoqiang, DONG Luying, and LI Youhui, An analysis of the potential in investment-cum-energy conservation in the chemical industry in China, Beijing: Energy Research Institute, 1992 (draft).

Editorial Committee of the China Environmental Yearbook, Zhongguo Huanjing Nianjian 1992 (China Environmental Yearbook 1992), Beijing: Zhongguo Huanjing Kexue Chubanshe, 1992.

$\mathrm{Fu}$ Shiye, Methods for conserving energy in the non-ferrous metals industry, Zhongguo Nengyuan (China Energy), No. 9, 1991.

Gan Liequan, Accelerate development of small-scale cogeneration, Zhongguo Nengyuan (China Energy), No. 4, 1989.

He Xuesheng, Quanguo dazhongxing qiye nengyuan guanli yu jieyue fangfa: diaocha baogao (Energy management and conservation methods at the nations large and medium enterprises: survey report), Jieneng Zhengce yu Jishu (Energy Policy and Technology), Wang Qingyi, ed., Beijing: Ministry of Energy, Comprehensive Utilization Office and China Energy Research Society, August 1991, pp 25-35.

Huang Jin-ping, Industry energy use and structural change: A case study of the People's Republic of China, Energy Economics, Vol 15, No 2, 1993.

Huang Ronghua, Using the economic benefits of energy conservation to repay loans: Shashi City's experience in popularizing energy-efficient loom switches, Zhongguo Nengyuan (China Energy), No. 5,1991.

Huang Yicheng, China's coal resource potential, Zhongguo Nengyuan (China Energy), No. $4,1989$.

Jiang Xianrong, Review of and prospects for China's energy conservation, Zhongguo Nengyuan (China Energy), No. 5, 1989.

Jiang Zhenping, Energy consumption and savings in China's urban and rural residential sectors, "Liuwu" Shiqi Zhongguo Jieyue Nengyuan Lunwen Xuanji (Selected Papers on China's Energy Conservation in the "Sixth Five-Year Plan"), Wang Bangcheng and XIN Dingguo, eds., Beijing: Nengyuan Chubanshe, 1989.

Levine, Mark D., Feng Liu, and Jonathan E. Sinton. China's energy system: Historical evolution, current issues, and prospects, Annual Review of Energy, 1992.

Li Guitian, Energy conservation programs in the metallurgical Industry for the Eighth Five-Year Plan, Zhongguo Nengyuan (China Energy), No. 9, 1991.

$\dagger$ For Chinese names we follow the Chinese convention of listing surname first. 
Lin Xiannuan, Declining energy intensity in China's industrial sector, The Journal of Energy and Development, Vol 16, No 2, 1992.

Liu Feng, Energy Use and Conservation in China's Building Materials Industry, Berkeley: Lawrence Berkeley Laboratory Report, forthcoming.

Liu Zhiping, Analysis of energy conservation investment in capital construction projects in the Sixth Five-Year Plan, Jie Neng (Energy Conservation), No. 7, 1987.

Liu Zhiping and Qin Shiping, Evaluation of energy conservation capital construction and technology updating programs, "Liuwu" Shiqi Zhongguo Jieyue Nengyuan Lunwen Xuanji (Selected Papers on China's Energy Conservation in the "Sixth Five-Year Plan"), Wang Bangcheng and Xin Dingguo, eds., Beijing: Nengyuan Chubanshe, 1989.

$\mathrm{Lu}$ Gengshan, Conserving energy through intensity reductions to improve enterprise economic efficiency, Zhongguo Nengyuan (China Energy), No. 3, 1991.

Lu Yingzhong, Fueling One Billion: An Insider's Story of Chinese Energy Policy Development, Washington, DC: Washington Institute Press, 1993.

Ministry of Energy (MOE), Some regulations regarding energy conservation in coal mines (trial implementation), Zhongguo Nengyuan (China Energy), No. 1, 1991.

Ministry of Metallurgy (MOM), Zhongguo Gangti Gongye Nianjian (China Steel Industry Yearbook), Beijing: Zhongguo Yejin Gongye Chubanshe, various editions 1988-1992.

Ministry of Metallurgy (MOM), Office of Energy, statistical materials on energy use in the metallurgical industry, date unknown.

Shi Yuexun, Techniques for coal powder injection with high oxygen and high air temperature, Yejin Nengyuan (Metallurgical Energy), No. 4, 1991.

Sinton, Jonathan E. Interviews with planning and energy conservation officials, Beijing and Nanjing, May, 1994.

Sinton, Jonathan E. and Mark D. Levine. Changing energy intensity in Chinese industry, Energy Policy. March, 1994.

Sinton, Jonathan E., William Davis, Jiang Zhenping, Mark D. Levine, Liu Feng, Zhuang Xing, Jiang Kejun, and Zhou Dadi, eds. China Energy Databook. Lawrence Berkeley Laboratory Report LBL-32822.Rev.2, revised June 1993.

State Planning Commission (SPC), Department of Resources Conservation and Integrated Utilization, ed., Ziyuan Heli Liyong Shouce (Rational Resources Utilization Handbook), Zhongguo Beijing: Kexue Jishu Chubanshe, 1992.

State Statistical Bureau (SSB), Zhongguo Tongji Nianjian 1992 (China Statistical Yearbook 1992), Beijing: Zhongguo Tongji Chubanshe, 1993.

State Statistical Bureau (SSB), Zhongguo Tongji Zhaiyao 1994(China Statistical Abstract 1994), Beijing: Zhongguo Tongji Chubanshe, 1994.

State Statistical Bureau (SSB), Industry and Transport Statistics Department, Zhongguo Nengyuan Tongji Nianjian 1991 (China Energy Statistical Yearbook 1991), Beijing: Zhongguo Tongii Chubanshe, 1992.

Wang Bingxin, Steam self-supply technology and waste heat boilers at small-scale nitrogenous fertilizer plants, Yure Guolu (Waste Heat Boilers), Beijing: Jianzhu Cailiao Chubanshe, 1990.

Wang Gang, Energy consumption in the building materials industry, Jianzhu Gongye Xinxi (Building Materials Industry Information), No. 22, 1991. 
Wang Jianli, Technological progress is a key to conserving energy and reducing intensity in the iron and steel industry in the Eighth Five-Year Plan, Yejin Nengyuan (Metallurgical Energy), No. 3, 1991.

Wang Qingyi, Guowai Zhuyao Gongye Chanpin Danwei Haoneng Diaocha: Yanjiu Baogao (Survey of Energy Intensities of Major Industrial Products in Foreign Countries: Research Report), Beijing: Energy Research Institute, January 1993.

Wang Ruwu, Suggestions regarding cogeneration development in China, Jie Neng (Energy Conservation), No. 11, 1991.

Wang Shumao, Zhou Fengqi, Zhou Dadi, Wang Bangcheng, Liu Zhiping, Dai Yande, $\mathrm{Hu}$ Xiaoqiang, Dong Luying, and Li Youhui. The investment-energy conserving curve of the building materials industry of China, Beijing: Energy Research Institute, December 1991 (draft).

Whiting, Susan H., Contract incentives and market discipline in China's rural industrial sector, conference paper presented at The Evolution of Market Institutions in Transition Economies, Ann Arbor: University of Michigan, Department of Political Science, July 1993.

Wirtshafter, Robert M., and Ed Shih, Decentralization of China's electricity sector: Is small beautiful?, World Development, Vol. 18, No. 4, 1990.

$\mathrm{Wu}$ Xichun and Meng Qinsheng, Progress and prospects in energy conservation in China's iron and steel industry, Yejin Nengyuan (Metallurgical Energy), No. 2, 1991.

Xiao Zhipeng, Energy consumption and conservation in China's non-ferrous metals industry, 1991 Nian Quanguo Jieneng Xuanchuanzhou Jieneng Baogao Wenji (Collected Energy Conservation Papers from the 1991 National Energy Conservation Propaganda Week), Beijing: Nengyuan Chubanshe, October, 1991.

$\mathrm{Xu}$ Derui, Woguo gangtie gongye jieneng jishu gaizao de xiankuang yu zhanwang (Current issues and prospects in energy conservation in China's iron and steel industry and prospects for the future), forthcoming.

Yang Fuqiang, Nathan Martin, and Mark D. Levine, A Review of China's Energy Policy, Berkeley: Lawrence Berkeley Laboratory, forthcoming.

Ye Qing, Outline of the Fifth Conference on Energy Conservation: Report to the Energy Conservation Office of the State Council," Zhongguo Nengyuan (China Energy), No. 5, 1989.

Yin Ruiyu, Increase awareness of energy conservation, open up a new era of energy conservation in the metallurgical industry: Speech at the Seventh National Conference on Energy Conservation, Yejin Nengyuan (Metallurgical Energy), No. 4, 1991.

Zeng Guangan, Reappraisal of energy conservation in the chemical industry, Zhongguo Nengyuan (China Energy), No. 9, 1992.

Zhao Yuying, Analysis of technology renovation during the Seventh Five-Year Plan, Guoneiwai Zhuyao Chanpin Danhao Nengyuan Yanjiu Wenji (Collected paper on Unit Energy Consumption of Major Domestic and Foreign Products), Guanming Ribao Chubanshe, 1988.

Zhou Fengqi, Progress of energy conservation in China, Zhongguo Nengyuan (China Energy), No. 1, 1989.

Zhu Liangdong, Achievement of energy conservation in the past decade and targets for the future, Zhongguo Nengyuan (China Energy), No. 10, 1991. 